\title{
On the prosody and syntax of DPs: evidence from Italian noun adjective sequences
}

\author{
Vicole Dehé • Vieri Samek-Lodovici
}

\begin{abstract}
This study tests a syntactic property-namely the availability of N- vs. NP-raising in DPs - through prosodic means. The opposition between N- and NPraising is central to the ongoing debate about the internal representation of DPs, yet it often eludes testing by syntactic means alone. As we show in this study, the two syntactic hypotheses are instead neatly distinguished by the distinct prosodic phrasing predicted by each operation. In this paper, we present the results of an empirical experiment designed to test the prosodic phrasing of N-A and A-N sequences in Italian and the corresponding syntactic implications. As prosodic cues, we use syllabic and word lengthening effects induced by phonological phrase boundaries. According to our results, A and $\mathrm{N}$ share the same phonological phrase in both orders. Regarding the syntactic implications of this finding we show that under all current models of syntax-prosody mapping the underlying syntactic structure responsible for the attested prosodic phrasing must necessarily rely on N-raising. Finally, we propose an analysis of Italian DPs where the N-raising operation found necessary in light of the attested prosodic phrasing is reconciled with the evidence for DP-internal phrasal movement discussed in Cinque (2005, 2006).
\end{abstract}

Keywords Italian · N-/NP-raising · DP-structure · Head v. phrasal movement · Prosodic phrasing $\cdot$ Prosodic boundaries

N. Dehé $(\bowtie)$

Institut für Englische Philologie, Freie Universität Berlin, Habelschwerdter Allee 45, 14195, Berlin, Germany

e-mail: ndehe(a)edat fu-berlinde

V. Samek-Lodovici $(\bowtie)$

Department of Italian, University College London, Gower Street, London WC1E 6BT, UK

e-mail: v.samek-lodoviciajucl ac.uk

Konstanzer Online-Publikations-System (KOPS)

URL: http://nbn-resolving.de/urn:nbn:de:bsz:352-147111 


\section{Introduction}

The last fiftee years have seen a still on-going debate about the underlying syntactic representation of DPs and in particular Romance N-A sequences involving attributive adjectives (henceforth referred to as 'direct modificatio adjectives' following Sproat and Shih's 1991 terminology). Since Cinque's seminal 1994 study identifying A-N as the base generated order for both Romance and Germanic languages, two main hypotheses have emerged to explain the mirror N-A order found in Romance. The $\mathrm{N}$-raising hypothesis maintains that $\mathrm{N}$ raises as a head to the left of a preceding AP projection (see among others Sproat and Shih 1991; Crisma 1991, 1993; Valois 1991; Bernstein 1991, 1993; Cinque 1994; Zamparelli 1995; Longobardi 1994, 2001, 2005; Kishimoto 2000; Rutkowski and Progovac 2006; Willis 2006; Pereltsvaig 2006; Artiagoitia 2006). The NP-raising hypothesis instead proposes that what moves is the entire NP (e.g., Bhattacharya 1998; Laenzlinger 2000; Alexiadou 2001; Shlonsky 2004; Knittel 2005; Cinque 2005, 2006). Within a structure à la Cinque (2005) where AP occurs in the specifie of a functional projection FP dominated by an agreement phrase as shown in (1), the N-raising analysis requires $\mathrm{N}$ to move into $\mathrm{Agr}^{0}$ through $\mathrm{F}^{0}$ as shown in (2), whereas the NP-raising alternative moves NP into SpecAgrP as shown in (3).

(1) Base-generated structure: $\left[\mathrm{AgrP} \mathrm{Agr}^{0}\left[\mathrm{FP}^{\mathrm{AP}} \mathrm{F}^{0}[\mathrm{NP} \mathrm{N}]\right]\right]$

(2) N-raising: [AgrP $\left.\quad \mathrm{N}_{\mathrm{i}}\left[\mathrm{FP} A P t_{i}\left[\mathrm{NP} \mathrm{t}_{\mathrm{i}}\right]\right]\right]$

(3) NP-raising: [AgrP $\left.\mathrm{NP}_{\mathrm{i}} \operatorname{Agr}^{0}\left[\mathrm{FP} \mathrm{APF}^{0} \mathrm{t}_{\mathrm{i}}\right]\right]$

The two alternative hypotheses are notoriously difficul to tell apart by syntactic tests alone. They are however neatly distinguished by the prosodic phrasing they predict. As we will discuss in detail, all current major models of the syntax-prosody mapping - e.g., Nespor and Vogel (1986), Selkirk (1986, 2000), Ghini (1993), Truckenbrodt (1995, 1999)-predict that an N-A sequence will be parsed into a single shared phonological phrase like (4a) under N-raising, whereas it would require two distinct phrases as shown in (4b) under NP-raising.

(4) a. $\left(\mathrm{N}_{\mathrm{i}} \mathrm{AP}\right)_{\mathrm{pp}}$

b. $\quad\left(\mathrm{NP}_{\mathrm{i}}\right)_{\mathrm{pp}}(\mathrm{AP})_{\mathrm{pp}}$

In this paper we present the results of an experimental reading study testing the prosodic phrasing of N-A and A-N sequences sharing the same $\mathrm{N}$ and $\mathrm{A}$, thus aiming at resolving the opposition in (4). As a robust prosodic cue, the experiment tested syllabic and word lengthening induced by phonological phrase boundaries (Nespor and Vogel 1986; Beckman and Edwards 1987, 1990, 1991; Hayes 1988; Wightman et al. 1992; Ghini 1993; Cruttenden 1997; Post 2000; Vaissière 1983; among others). It uncovered a statistically highly significan lengthening of the second word of A-N and $\mathrm{N}-\mathrm{A}$ sequences in its entirety, and of its fina and lexically stressed syllables (shown in bold in (5) below). These results show that adjective and noun are wrapped in a single phonological phrase ( $\mathrm{pp}$ ) independently of their order, as symbolized by the round parentheses in the examples in (5). 
(5) a. (pre.la.to po.ten.te) $)_{\mathrm{pp}}$

prelate powerful

b. (po.ten.te pre.la.to) $)_{p p}$

powerful prelate

Our experimental results provide strong independent support for the N-raising hypothesis and the corresponding syntactic representation in (2) above. Yet this outcome may at firs appear surprising, since it is at odds with convincing arguments against generalized N-raising and in support of DP-internal phrasal movement in Cinque $(2005,2006)$. As we show in the second part of this study, closer examination of the syntax of N-raising reveals that it is limited to the closest AgrP and that any further raising of the noun requires pied-piping of the entire AgrP consistently with Cinque's empirical and theoretical results. Head and phrase raising co-exist, but target distinct syntactic categories within DP.

The implications of the prosodic phrasing attested in our experiment also extend to the analysis of Italian overt subjects, supporting their occurrence in a projection higher than TP as proposed in Barbosa (1995), Alexiadou and Anagnostopoulou (1998), Rizzi (2004), Cardinaletti (2004), Frascarelli (2007). On the prosodic side, we will show that only Truckenbrodt's $(1995,1999)$ model can consistently extend the syntax-prosody mapping found for N-A sequences to A-N sequences as well.

We start in Sect. 2 with a description of the experiment and its results relative to the prosodic phrasing of A-N and N-A sequences. The syntactic implications of this prosodic phrasing are discussed in Sect. 3 , where we show how current models of syntax-prosody mapping require an N-raising representation of A-N and N-A sequences as well as a higher syntactic position than normally assumed for Italian overt subjects. Finally in Sect. 4 we examine Cinque's arguments against generalized Nraising, firs showing that they do not exclude local N-raising of the kind advocated in this paper and then arguing for an analysis where N-raising and phrasal raising of functional projections à la Cinque co-exist, with their application governed by the principles responsible for movement locality proposed in Cinque $(2005,2006)$.

\section{The prosodic phrasing of Italian $\mathrm{A}-\mathrm{N}$ and $\mathrm{N}-\mathrm{A}$ sequences: an experimental study}

The experiment described in this section was designed to test the prosodic phrasing of Italian N-A and A-N sequences each involving an invariant direct modificatio adjective expressing an evaluative quality of the noun (such as ugly or powerful). Unlike other adjectival classes, these adjectives may both precede and follow the noun they modify while retaining their original meaning. ${ }^{1}$ This makes them ideal for investigating the presence of N- vs. NP-raising based on the prosodic properties of the

\footnotetext{
${ }^{1}$ As discussed at length in Cinque (2006), the distribution of Italian adjectives relative to nouns depends on whether they belong to the direct or indirect modificatio classes identifie in Sproat and Shih (1991) (see also Alexiadou 2001 and Knittel 2005). Direct modificatio adjectives-i.e., attributive adjectives expressing appositive properties, typically involving an individual level and non-restrictive interpretation-may generally both precede and follow the noun they modify. In contrast, indirect modificatio adjectivesi.e., predicative adjectives usually showing a stage-level and restrictive interpretation similar to that of
} 
corresponding N-A and A-N sequences. We examined domain-fina lengthening effects, which have been established as a robust cue to prosodic boundaries in much previous research. As Vaissière (1983:61) points out, there are four kinds of lengthening phenomena that mark the right boundary of a word or phrase: (i) lengthening of the very last syllable of a word or phrase, (ii) lengthening of the last stressed syllable in a phrase, (iii) lengthening of the entire last word in a phrase, and (iv) lengthening of the last sentence in a read paragraph. The firs three kinds of lengthening are relevant to our study and were tested for Italian A-N/N-A sequences. As for the firs (lengthening of the very last syllable of a prosodic domain), Cruttenden (1997:33) points out that it is a productive prosodic process attested in most languages and likely to constitute a universal property of prosodic phrasing (see also Hayes 1988; Wightman et al. 1992; Beckman and Edwards 1987, 1991; Post 2000). The syllable immediately preceding a prosodic boundary is lengthened regardless of whether it carries the lexical stress of the word (Cruttenden 1997:33; Beckman and Edwards $1987,1990,1991)$. This is illustrated in (6) where the fina syllable of a hypothetical three-syllabic word is lengthened due to the phonological phrase boundary immediately following it; the affected syllable is shown in bold.

(6) Pre-boundary lengthening: $\ldots \sigma . \sigma . \sigma o . \sigma \quad \sigma . \sigma . \sigma:)_{\mathrm{pp}}(\sigma . \sigma . \sigma \ldots$

The second lengthening process affects the syllable carrying lexical stress in the word immediately preceding the prosodic boundary. For example, a three-syllable word with penultimate lexical stress like the one in (7) below would have its penultimate syllable (in bold) further lengthened due to the following boundary. Lengthening in this case is arguably caused by the prosodic head of the pp, which in Italian always falls on the rightmost word of the $\mathrm{pp}$, thus adding additional prosodic prominence to its stressed syllable (Selkirk 1984, 1986, 1995, 2000, 2004; Hammond 1984;

adjectival predicates in corresponding relative clauses-may only follow the noun (further properties distinguishing between the two classes are discussed in Cinque 2006 and references therein). As Cinque explains, this gives rise to a systematic alternation. Pre-nominal adjectives unambiguously belong to the direct-modificatio class. Post-nominal ones, on the other hand, may belong to either class, thus giving rise to an ambiguous interpretation. For example, the pre-nominal adjective potenti in (i) may only be interpreted as an individual level property (Rome's prelates are typically powerful) and non-restrictively (we are speaking of all of Rome's prelates, who are also powerful; not of that subset of Rome's prelates that are powerful). The same adjective in postnominal position in (ii), on the other hand, is ambiguous between the interpretation just described and the stage-level restrictive interpretation associated with the indirect modificatio class (the subset of Rome's prelates that are currently powerful).

(i) $\mathrm{i}$ potenti prelati di Roma

the powerful prelates of Rome

(ii) $\mathrm{i}$ prelati potenti di Roma the prelates powerful of Rome

As mentioned above, the A-N and N-A sequences used in our experiment all involve direct modificatio adjectives, since indirect modificatio adjectives cannot precede a noun. To eliminate the potential ambiguity of postnominal adjectives in the N-A sequences we placed both sequences in indefinit DPs. The generic, non-specifi interpretation of the indefinit DPs used in our experiment is inconsistent with the stage-level and restrictive interpretation associated with indirect-modificatio adjectives, ensuring that the adjective is interpreted as the same direct modificatio adjective in both sequences (on the relevance of genericity for the distribution and interpretation of Romance adjectives see also Crisma 1993). 
Halle and Vergnaud 1987; Edwards and Beckman 1988; Hayes 1995; Truckenbrodt 1995). An Italian example from Ghini (1993) showing vocalic lengthening in the stressed syllables of the pp-fina words is provided in (8).

(7) Stressed-syllable lengthening: $\ldots \sigma . \sigma . \sigma . \sigma \quad \sigma . \sigma: \sigma)$ pp $(\sigma . \sigma . \sigma \ldots$

(8) (i ca.ri.bù $n[a:] . n i)_{p p}$ (sono es.t[i:]n.ti)

the caribous dwarf are extinct

'Dwarf caribous are extinct.'

Finally, the last word of a prosodic domain has also been observed to lengthen (Umeda and Quinn 1981; Hellmuth 2004). For Italian, Nespor and Vogel (1986:176) observe that pp-boundaries induce lengthening of the domain-fina word, an effect possibly simply measuring the cumulative effect of the two lengthening processes introduced above. For example, they note how the word pasticcini is longer when it occurs pp-finall in (9b) than when occurring pp-internally as in (9a).

(9) a. Ho mangiato (dei pasticcini ripieni) $)_{\mathrm{pp}}$.

(I) have eaten some donuts fille

'I have eaten some fille donuts.'

b. Ho mangiato (dei pasticcini $)_{p p}(\text { ripieni) })_{p p}$ (di cioccolata) $)_{p p}$.

(I) have eaten some donuts fille of chocolate

'I have eaten some chocolate-fille donuts.'

Together, the above lengthening processes provide a powerful tool for determining the prosodic phrasing of Italian N-A and A-N sequences. Consider, for example, the sequences in (10) below, where lexical stress falls on the penultimate syllable in both words (the stressed syllable is shown in bold).

(10) A-N: po.ten.te pre.la.to powerful prelate

$\mathrm{N}-\mathrm{A}$ : pre.la.to po.ten.te

If both sequences are wrapped into a single pp ending at the right edge of the sequence as in (11), then lengthening will only affect the fina word (in bold) and its last two syllables (in capitals). Crucially, the duration of the affected syllables and the word itself is predicted to change according to its position in the sequence, with increased length expected when the word occurs second, i.e. immediately preceding the pp-boundary. For example, under the phrasing shown in (11), the noun prelato and the syllables 'la' and 'to' in it are predicted to be longer under the A-N order than the N-A one. Due to the inherent symmetry of the example, the same holds for the adjective and its fina syllables, which are predicted to be longer in N-A sequences.
(11) A-N: ... po. ten.te
pre.LA.TO $)_{\mathrm{pp}}(\ldots$
$\mathrm{N}-\mathrm{A}:$. . pre.la.to
po.TEN.TE $)_{\mathrm{pp}}(\ldots$

The distribution of word and syllabic lengthening just illustrated is distinctive of the prosodic phrasing in (11). Let us call it its 'length signature'. Any other conceivable prosodic phrasing has a different length signature. Consider for example the three phrasings in (12)-(14) below, which together with (11) above exhaust the cases 
where the phrasing remains invariant across the two A-N and N-A sequences. If the sequences are parsed into a single pp but with no pp-boundary following the last word, as in (12), then no lengthening occurs and the relative length of the relevant syllables and words remains constant independently of sequence order; for example, the syllables 'la' and 'to' of the noun 'prelato' would remain equally long across the A-N and N-A orders.

If on the other hand $\mathrm{A}$ and $\mathrm{N}$ are phrased into distinct pps each preceding a ppboundary as in (13) then the relevant syllables and word are lengthened across the board, again predicting equal length independently of the sequence order. Finally, if only the firs word immediately precedes a pp-boundary, as in (14), then lengthening only occurs in sequence-initial position. None of these cases thus predicts the increased length in sequence fina position associated with (11) above.

(12) A-N: (... po.ten.te pre.la.to ... $)_{\mathrm{pp}}$

N-A: (...pre.la.to po.ten.te ...) $)_{\mathrm{pp}}$

(13) A-N: ‥po.TEN.TE $)_{\mathrm{pp}}(\text { pre.LA.TO })_{\mathrm{pp}}$

N-A: $\quad$..pre.LA.TO $)_{\mathrm{pp}}$ (po.TEN.TE)

(14) A-N: ...po.TEN.TE) $)_{\mathrm{pp}}$ (pre.la.to ...

N-A: _. pre.LA.TO) $)_{p p}$ (po.ten.te ...

Many additional possible phrasings are conceivable once the two sequences are allowed to receive different, non-parallel phrasings. As the reader may easily verify none of them matches the length signature of phrasing (11) because every nonparallel case necessarily involves one of the phrasing described in (12)-(14) for at least one of the A-N and N-A sequences. Consequently, they all show a length signature distinct from (11).

In our experiment, we measured the length signature of a set of A-N and N-A sequences embedded in carrier sentences. The results closely match the prosodic phrasing in (11). The details of the experiment are described below.

\subsection{Materials}

The experimental materials consisted of 5 adjective-noun pairs involving the same direct-modificatio adjective presented under A-N and N-A order. The 5 pairs were contained in 20 carrier sentences, 10 of which were constructed such that the target sequence was the subject of the sentence (cf. (15) and (16)), while the other 10 were constructed such that the target sentence was the object of the sentence (cf. (17) and (18)). For each subject and object position, 5 sentences represented the A-N order (exemplifie in (15) and (17)), while the other 5 represented the N-A order (as in (16) and (18) below). Examples (15)-(18) show the four sentence types for one adjectivenoun pair. The full experimental materials are provided in the appendix at the end of the article.

(15) Un po.ten.te pre.la.to può imporre il suo punto di vista anche al papa. a powerful prelate can impose the his point of view even to-the pope

(16) Un pre.la.to po.ten.te può imporre il suo punto di vista anche al papa. a prelate powerful can impose the his point of view even to-the pope 
(17) Abbiamo contattato un po.ten.te pre.la.to con il permesso del papa. (we) have contacted a powerful prelate with the permission of-the pope

(18) Abbiamo contattato un pre.la.to po.ten.te con il permesso del papa. (we) have contacted a powerful prelate with the permission of-the pope

In addition to these items, 35 sentences were part of the materials which were originally designed to test the prosodic phrasing of adverbs in VPs. They were part of another study and thus irrelevant to the present discussion. Moreover, the materials contained 46 fille sentences, adding up to 101 items overall. In the experimental design, these 101 items were pseudo-randomized under the usual restrictions.

\subsection{Participants, apparatus and procedure}

The experiment was carried out with 12 untrained native speakers of Italian (8 female, 4 male). At the time of the testing, they were unaware of the aim of the study. The target utterances were shown individually on a computer screen using Microsoft PowerPoint, thus supporting an out-of-the-blue broad-focus reading. ${ }^{2}$ The participants were instructed to familiarize themselves with each sentence before reading it out aloud, and then to move on to the next sentence. They were asked to produce each sentence as naturally as possible at a normal speech rate. Each sentence was read only once by each participant. ${ }^{3}$ The list of target items was preceded by fve practice items to familiarize the participants with the procedure. All utterances were recorded to a Samsung laptop computer using an AKG C444 headset microphone with AKG B29L battery power supply and Cool Edit ${ }^{\mathrm{TM}} 96$ software. The recordings were later digitized into individual sound file using the same software. The individual sound file were analyzed in PRAAT (Boersma 2001; Boersma and Weenink 2008).

\subsection{Data treatment}

Overall, the 12 speakers produced 240 target sentences: 60 sentences in each of the four data sets exemplifie in (15) to (18) above. Of the 240 sentences, 15 contained speech errors and were discarded from the analysis. For each item that entered the analysis, the length of the two target words (A and N), and the length of the stressed and fina syllables were measured, and the mean values calculated. The results were coded with respect to a) the order of $\mathrm{A}$ and $\mathrm{N}$, and b) the syntactic function of the relevant constituent (subject vs. object).

\footnotetext{
${ }^{2}$ In Italian, focus generally triggers a phrase boundary at its right edge (Frascarelli 2000). The absence of such intermediate boundaries in our experimental results further confirm the absence of an accidental narrow focus interpretation of $\mathrm{N}$ and $\mathrm{A}$ in the respective $\mathrm{N}-\mathrm{A}$ and $\mathrm{A}-\mathrm{N}$ sequences.

${ }^{3}$ In much work on prosodic phonology, test sentences are read more than once by each participant to allow for the subsequent removal of erroneous items. However, these studies usually test very few participants (e.g., 2 speakers per language, 3 repetitions in Elordieta et al. 2005). As suggested by an anonymous reviewer the higher number of participants in our study balances out the lack of repetitions.
} 
a.

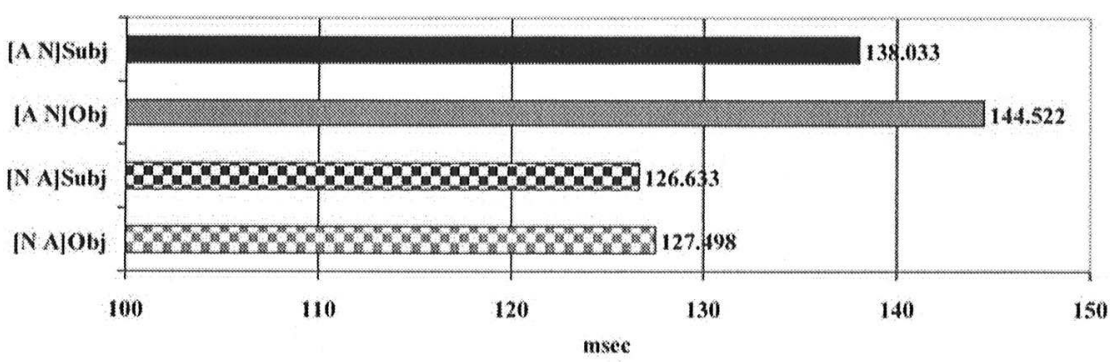

stressed syllable of $\mathrm{N}$

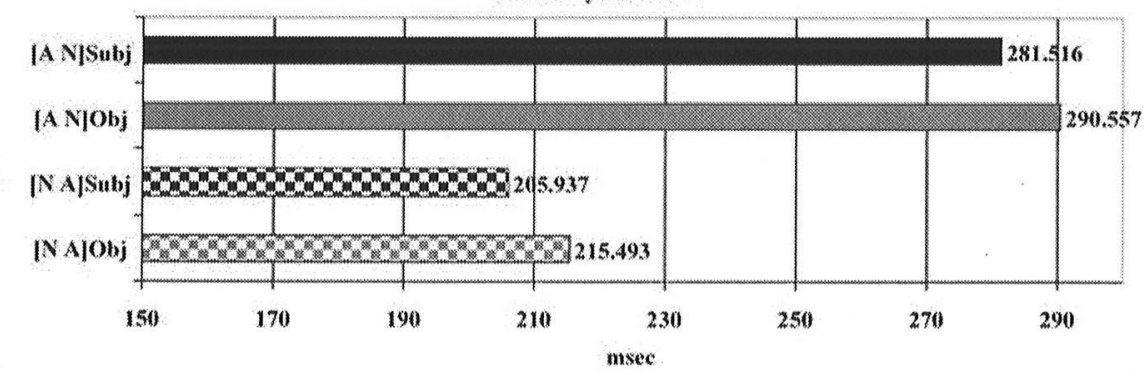

N (word length)

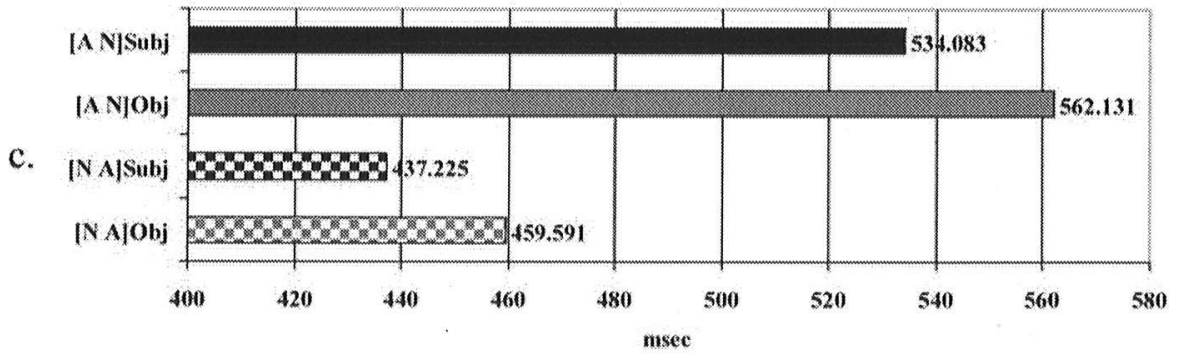

Fig. 1 Length of the fina syllable of $\mathrm{N}$ (panel a), the stressed syllable of $\mathrm{N}$ (panel b) and the full $\mathrm{N}$ (panel c) in the two word orders, in subject and object position

\subsection{Results}

As outlined above, three kinds of fina lengthening phenomena were addressed. Overall, the length of all target elements (fina syllable, stressed syllable, full word) was clearly affected by the position of the respective word. They were longer when the respective word was second in its target sequence. Specificall, in both subject and object position, the following effects were recorded:

(i) The fina syllable of $\mathrm{N}$, the stressed syllable of $\mathrm{N}$, and $\mathrm{N}$ itself were longer when $\mathrm{N}$ followed $\mathrm{A}$ than when $\mathrm{N}$ preceded $\mathrm{A}$ (cf. Fig. 1).

(ii) The fina syllable of $A$, the stressed syllable of $A$, and $A$ itself were longer when A followed $\mathrm{N}$ than when A preceded $\mathrm{N}$ (cf. Fig. 2). 
final syllable of $A$

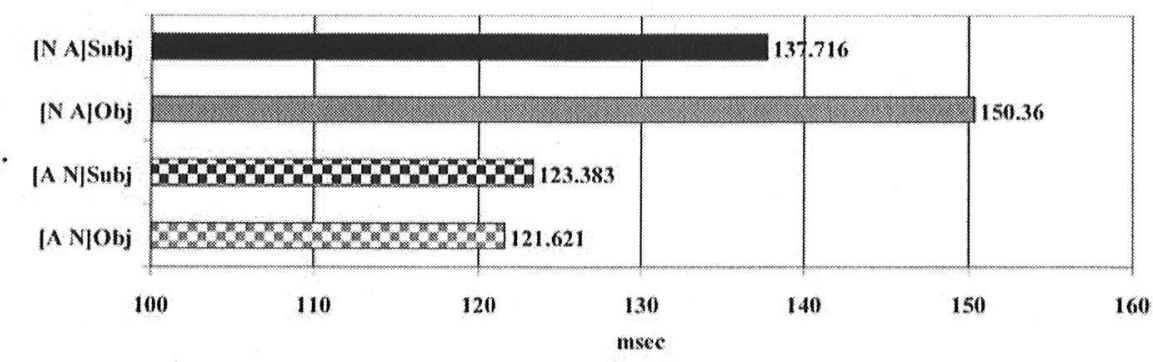

stressed syllable of $A$

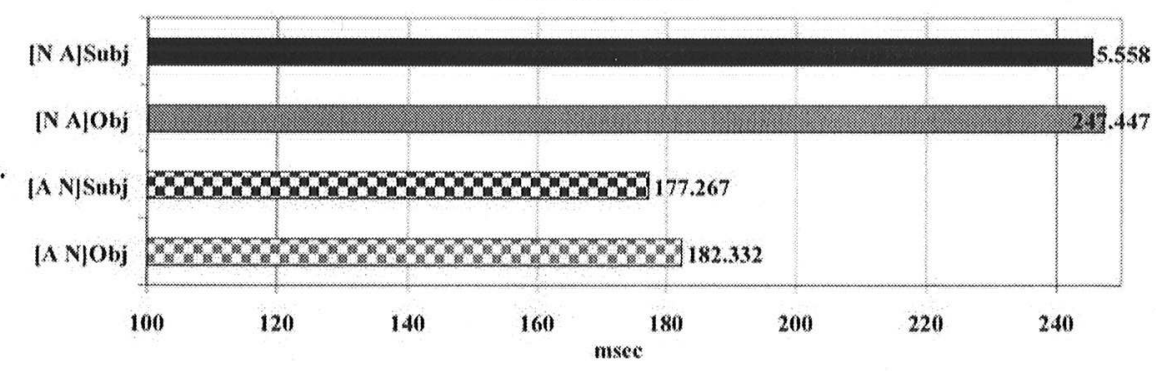

A (word length)

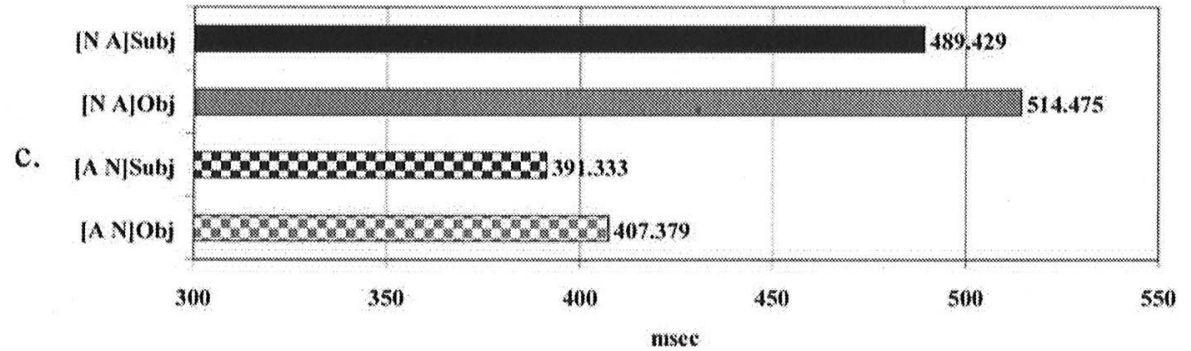

Fig. 2 Length of the fina syllable of A (panel a), the stressed syllable of A (panel b) and the full A (panel c) in the two word orders, in subject and object position

The results for $\mathrm{N}$ and its stressed and fina syllables are illustrated by the three panels in Fig. 1. The firs panel shows how the fina syllable of $\mathrm{N}$ increases in length when $\mathrm{N}$ is fina in either subject (firs row) or object position (second row) than when $\mathrm{N}$ precedes A (third and fourth rows). The next two panels in Fig. I show the corresponding lengthening effects for the stressed syllable of $\mathrm{N}$ and for $\mathrm{N}$ itself according to the same layout. Figure 2 shows the corresponding lengthening effects for $\mathrm{A}$ in $\mathrm{N}-\mathrm{A} / \mathrm{A}-\mathrm{N}$ sequences.

The duration values were submitted to an analysis of variance with the factors POSITION (2 levels: A-N vs. N-A) and SYNTACTIC FUNCTION (2 levels: subject vs. object). The scores were pooled over both speakers and items, and the $\alpha$ level determining the significanc threshold was set at 0.05 (significant) $/ 0.0$ (highly significant) The most relevant results for the present study concern the factor position. 
The analysis of variance showed that the lengthening of $\mathrm{A}$ and $\mathrm{N}$ in their entirety was highly significan in both the item and speaker analyses. POSITION was also highly significan across item and speaker analyses for the stressed syllable of both A and N. As for the fina syllable, POSITION was highly significan in the speaker analysis for $\mathrm{A}$ and in the item analysis for $\mathrm{N}$.

The SYNTACTIC FUNCTION factor-less relevant to the goals of this paper-was found significan only in the subject analyses for full $\mathrm{A}$ and $\mathrm{N}$ and for the stressed syllable of $\mathrm{N}$, showing that these elements may be longer in object position than they are in subject position. At present, we can only speculate that these results might be related to the temporal organization of the sentence such that initial parts of the sentence are said more quickly than later parts since more material is yet to be produced, but nothing hinges on this in this paper. More importantly, no interaction was found between the factors POSITION and SYNTACTIC FUNCTION in any of the subparts of the analysis, confirmin that POSITION affects the length of the target element in subject and object constituents alike. ${ }^{4}$

In conclusion, the statistical analysis confirm the lengthening effects described above which in turn entail the following two conclusions:

(i) There is a pp-boundary after the target sequence in both word orders and regardless of whether the sequence functions as subject or object of the carrier sentence.

(ii) There is no pp-boundary separating $\mathrm{A}$ and $\mathrm{N}$ in either order, neither in subject nor in object position.

Needless to say, these are exactly the properties uniquely characterizing the prosodic phrasing in (11) above. The next section will examine what underlying syntactic representation may determine the attested prosodic phrasing.

\footnotetext{
${ }^{4}$ The fact that SYNTACTIC FUNCTION did not reach significanc in any crucial sense also implies that the boundary following the subject and the boundary following the object in a Subj V Obj PP-Adjunct structure are of the same type/strength. In recent experimental work on Romance prosodic phrasing, Italian SVO sentences were found to be preferably phrased (S)(VO) if the subject was branching, and (SVO) or (SV)(O) if the subject was non-branching (D'Imperio et al. 2005; Frota et al. 2007). Since the subject phrases in our data are branching, based on these research results we expect (S)(VO)(Adjunct) phrasing in our data, i.e., exactly what we found.

Note that in a model that assumes at least two phrasal levels between the Prosodic Word and the Utterance, such as Intonational Phrase, IP, and phonological phrase, pp (e.g., Nespor and Vogel 1986), the observed boundaries following subject and object could in principle relate to the edge of a $\mathrm{pp}$, as assumed here, or to the edge of an IP. The prosodic studies on Romance languages that distinguish between pps and IPs (see, in particular, Grice et al. 2005 on varieties of Italian) fin L\% and $\mathrm{H} \%$ boundary tones terminating IP, whereas there is no evidence for these tones in post-subject position in our data. Furthermore, according to Grice et al. (2005:374-378) IP-boundaries are absent following a left-dislocated subject, consistent with our analysis. Finally, since as mentioned above the post-subject boundaries are equivalent to post-object boundaries in strength, positing a post-subject IP-boundary would entail that post-object boundaries are also of the IP kind, in contrast with Frascarelli $(2000: 19,21,35)$ where post-object adjuncts are shown to follow a pp-boundary rather than an IP-boundary whenever focus is clause-wide, as is the case in our data. In conclusion, the tonal and non-tonal evidence available in our data supports the presence of post-subject and post-object pp-boundaries rather than IP-boundaries.
} 


\section{The syntactic representation of Italian $\mathrm{N}-\mathrm{A}$ and $\mathrm{A}-\mathrm{N}$ sequences}

Since the seminal research by Bernstein (1991) and Cinque (1994), a rich variety of studies have shown that Romance and Germanic nominal expressions share an identical underlying hierarchical structure where adjectives are generated to the left of nouns (but see Larson and Marušič 2004 and Abels and Neeleman 2006 for a different position). Cinque (2005) is particularly convincing in this respect as he shows that given some general necessary restrictions on the possible movement types, only the universal base-generated order $\angle D \# A N>$ (where ' $D$ ' stands for 'demonstrative' and '\#' stands for 'numeral') provides a suitable basis for the derivation of the cross-linguistically attested orders of D, \#, A, and N among the 24 that are logically possible. We therefore assume the order $\angle A N>$ as the base-generated order from which $\mathrm{A}-\mathrm{N}$ and $\mathrm{N}-\mathrm{A}$ sequences are derived.

As for the specifi structural position of A, while some studies follow Abney (1987) in allowing it to be part of the main spine of the structure as in (19a) belowe.g., Artiagoitia (2006) - we follow the majority of scholars and assume that $\mathrm{A}$ is generated in the specifie of a corresponding functional projection as in (19b); see for example Crisma (1991, 1993), Zamparelli (1995), Laenzlinger (2000), Shlonsky (2004), Knittel (2005), and Cinque $(2005,2006) .^{5}$

(19) a. $\ldots\left[\mathrm{AP} 1 \mathrm{~A}_{1}\left[\mathrm{AP} 2 \mathrm{~A}_{2}[\ldots[\mathrm{NP} N]\right.\right.$

$$
\text { b. } \ldots\left[\mathrm { FP } \mathrm { AP } _ { 1 } \mathrm { F } \left[\mathrm{FP} \mathrm{AP}_{2} \mathrm{~F}[\ldots[\mathrm{NP} \mathrm{N}] \quad \text { (assumed in this study) }\right.\right.
$$

$\mathrm{N}$-A sequences do not match the above structure and must therefore arise from movement of the noun to a functional projection above the adjective. For the sake of concreteness we identify this projection as Cinque's (2005) AgrP projection although the exact nature of this projection is irrelevant to the argument developed in this work. More relevant to our goals is the disagreement concerning whether the N-A order is obtained via N- or NP-raising to the left of the adjective. Under the above assumptions the N-raising hypothesis yields the structure in (20a), whereas the NPraising hypothesis yields the structure in (20b).

(20) a. N-raising: $\quad\left[\mathrm{AgrP} \_\mathrm{N} \quad\left[\mathrm{FP}\right.\right.$ AP $\left.\left.\mathrm{t}_{\mathrm{N}}\left[\mathrm{NP}_{\mathrm{N}}\right]\right]\right]$ b. NP-raising: [AgrP $\mathrm{NP}_{\mathrm{i}} \operatorname{Agr}\left[\mathrm{FP}\right.$ AP F t $\left.\mathrm{t}_{\mathrm{NP}}\right]$

\footnotetext{
${ }^{5}$ As pointed out in Svenonius (1994) and again in Cinque (2006), a structure à la Abney (1987) like (19a) cannot account for the occurrence of non-argumental adjectival modifier in prenominal adjectives, yet these are possible as shown by examples (1) and (2) below. Furthermore, the adjectival heads in (19a) are inconsistent with the head-movement analysis advocated in this study since they would block N-raising. Additional arguments supporting a phrasal analysis of NP-internal adjectives can be found in Pysz (2006), who examines problems related to the analysis of adjectival scope and the representation of postnominal adjectives, as well as Cinque (2006), who examines phrasal $\mathrm{A}^{\prime}$-movement, coordination, and codeswitching.
}

(1) La sempre accogliente villa di Giovanni. the always pleasant villa of John 'John's always pleasant villa.'

(2) La per molti versi ridicola biografi del Rossi. the for many sides ridiculous biography of-the Rossi 'Rossi's in many ways ridiculous biography.' 
The main syntactic arguments supporting these opposite claims are examined in Sect. 4 ; in this section we focus instead on the prosodic phrasing predicted by each representation under current models of the syntax-prosody mapping, which we then compare against the prosodic phrasing attested in our experiment. We start with $\mathrm{N}-\mathrm{A}$ sequences and then move to A-N sequences in Sect. 3.2.

\subsection{Prosodic cues to the syntactic representation of N-A sequences}

All major models of the syntax-prosody mapping map the N-raising structure (20a) onto a single pp, as illustrated in (21a) below, and the NP-raising structure (20b) onto separate pps as shown in $(21 \mathrm{~b})$ (when matched against our experimental results NP and AP should of course be conceived of as containing a single noun and adjective, respectively). This identifie the N-raising structure in (20a) as the underlying syntactic representation of the $\mathrm{N}-\mathrm{A}$ sequences examined in our experiment.

$$
\begin{array}{llll}
\text { (21) } & \text { a. } & (\ldots \mathrm{N} & \mathrm{AP}) \\
& \text { b. } & (\ldots \mathrm{NP}) & (\mathrm{AP})
\end{array}
$$

Below we examine how each model arrives at the above prediction. While some details may differ, crucially all models dictate that a maximal projection such as NP in the NP-raising structure is necessarily followed by a pp-boundary, thus determining the distinct predictions in (21).

Nespor and Vogel (1986)-Consider firs the detailed study of Italian prosodic phrasing in Nespor and Vogel (1986). Their model requires lexical heads to form their own pps, with an additional optional restructuring rule extending these same pps to the firs complement of the head (Nespor and Vogel 1986:168-173). ${ }^{6}$ Under this model $\mathrm{N}$ and $\mathrm{A}$ would therefore form their own pps in both structures (20a) and (20b). The restructuring rule would then successfully apply to the N-raising structure where AP occurs within the complement of the raised $\mathrm{N}$ and place $\mathrm{N}$ and AP into a single shared $\mathrm{pp}$. The same rule however would not apply to the NP-raising structure because in this structure AP is not part of the complement of N. NP and AP will each be phrased in a pp of their own, contrary to the phrasing attested in the experiment reported above.

Selkirk (1986) - The same predictions are made by the influentia model proposed by Selkirk (1986) requiring the left or right edge of a syntactic maximal projection to coincide with a corresponding pp-boundary. For Italian; this is commonly assumed to be the right edge. A pp-boundary must then follow the raised NP of (20b) and produce two distinct pps for NP and AP. The raised N of (20a) on the other hand escapes the requirement by being non-maximal, thus letting $\mathrm{N}$ and $\mathrm{AP}$ share the same pp.

\footnotetext{
${ }^{6}$ Nespor and Vogel's restructuring rule joins together the pp of the selecting head with the pp of the complement provided the latter is a non-branching complement. This latter condition ensures that the pp contains at most one 'clitic group', i.e. no more than a single lexical item. The N-A sequences examined in our experiment satisfy this condition because AP contains a single complement-less modifie -free adjective. Indeed Nespor and Vogel (1986:172) provide the example caribù nani-meaning 'caribous dwarf' - as an $\mathrm{N}-\mathrm{A}$ sequence sharing a single pp as a result of the restructuring rule
} 
Ghini (1993)-Closely following Selkirk, Ghini too provides a model for the prosodic phrasing of Italian that explicitly assumes a pp-boundary at the right edge of maximal projections. Ghini also examines additional principles of rhythmic organization that at firs may appear to allow for the parsing of the NP and AP in structure (20b) as a single pp. Ghini however states very clearly that these rhythmic principles never apply across the right edge of a maximal projection, thus subordinating them to Selkirk's right-edge rule. As Ghini points out, this restriction is necessary to prevent incorrectly phrasing a subject with a following verb, or an object with a following indirect object, postverbal subject, or higher adjunct. In all these cases the firs item is a maximal projection separated from the following items by a pp-boundary. Subordinating Ghini's principles to Selkirk's right-edge rule ensures that the attested separate phrasing remains unaltered. ${ }^{7}$ It follows that Ghini's model too predicts a pp-boundary after the raised NP of structure (20b). In fact, since Ghini's rhythmic principles are subordinated to Selkirk's right-edge rule, any analysis of the '(N A)' phrasing attested in our experiment in terms of Ghini's principles necessarily presupposes the lack of an NP-boundary and therefore the N-raising structure in (20a).

Truckenbrodt $(1995,1999)$ - A post-NP pp-boundary is also predicted under Truckenbrodt's model $(1995,1999$, see also the similar model in Selkirk 2000). Truckenbrodt's model is based on Optimality Theory (Prince and Smolensky 1993, 2004) and aims at capturing the effects of focus on prosodic phrasing across distinct languages. Since focus and stress do not play a role in our study we can limit our discussion to the two constraints governing the mapping of lexical projections onto pps. The firs constraint, AlignXP (XP, Right, pp, Right), recasts Selkirk's right-edge rule in terms of McCarthy and Prince's (1993) theory of generalized alignment by requiring the edge of every lexical maximal projection XP to be aligned with the right boundary of a pp. The effect is to introduce a pp-boundary immediately after every lexical XP, as in Selkirk (1986). The second constraint, Wrap-XP, requires that all the syntactic material dominated by the maximal projection of a lexical item be wrapped into a single pp. Wrap-XP may for example force all items dominated by a VP-node to be parsed into a single $\mathrm{pp}$.

Together, AlignXP and Wrap-XP predict separate pps for the NP-raising structure (20b). AlignXP requires a pp-boundary to coincide with the right edge of NP while Wrap-XP is satisfie by the wrapping of NP and AP each in a pp of its own.

A single shared $\mathrm{pp}$ is instead predicted for the $\mathrm{N}$-raising structure in (20a). As shown in Samek-Lodovici (2005) and further discussed later in this section, lexical heads raised to an empty functional head make the corresponding projection prosodically lexical, i.e., visible to prosodic constraints like Align-XP and Wrap-XP. ${ }^{8}$ The

\footnotetext{
${ }^{7}$ Some examples are provided in (22). Unless they are blocked from applying across the right edge of maximal projections, Ghini's principles of average weight, symmetry, and increasing units, would incorrectly predict a shared single pp for (22a) rather than the attested two. They would also predict the phrasing ' $(\mathrm{V})(\mathrm{Obj} \mathrm{XP})$ ' in (22b) and (22c) rather than the attested '(V Obj)(XP)'.

${ }^{8}$ The prosodic literature distinguishes the properties of overt lexical items, such as nouns and verbs, from the properties of overt functional items, such as determiners and auxiliaries (e.g., Truckenbrodt 1999). What makes an item prosodically lexical or functional, however, are the intrinsic properties of the item itself, i.e., whether it is listed as lexical or functional in the lexicon. In particular, a lexical item head-raised into an empty functional head remains prosodically lexical. For example, the prosodic phrasing of Italian
} 
raised $\mathrm{N}$ in (20a) thus makes AgrP visible to Wrap-XP, which wraps all material dominated by AgrP, namely $\mathrm{N}$ and AP, into a single pp. This pp also satisfie AlignXP, because the right edge of all available maximal projections, i.e., AgrP and AP, are properly aligned with a pp-boundary. Crucially, $\mathrm{N}$ itself is not maximal and therefore not subject to AlignXP, ensuring that no pp-boundary follows $\mathrm{N}$.

Truckenbrodt (1995)-The last model is a variant of the model just examined where AlignXP is replaced by the interaction of two constraints. The firs one, StressXP, requires lexical XPs to express the prosodic peak of a pp (this peak, the prosodic head of the pp, provides XP with pp-level stress, hence the name of the constraint). The second constraint, Align-pp(pp, Right, Head(pp), Right), ensures that the prosodic head of the $\mathrm{pp}$ is aligned with the right boundary of that $\mathrm{pp}$. Together these two constraints once again ensure that lexical XPs are always immediately followed by a pp-boundary. On the one hand Stress XP forces an XP to express the head of a pp, on the other hand Align-pp ensures that the same pp-head is immediately followed by a pp-boundary. The overall effect is a pp-boundary after the XP. It follows that under this model, too, the NP-raising structure projects two distinct pps to ensure that the NP and AP are each assigned their own right-aligned pp-head. The N-raising structure, on the other hand, allows for a single pp grouping noun and adjective together with its prosodic head on the AP. This phrasing satisfie both constraints. The pp-head on AP is aligned with the pp-boundary following the adjective. Furthermore, since the AP occurs within the complement of the head hosting N, the pp-head on AP too lies within the projection headed by $\mathrm{N}$-namely AgrP - thus satisfying StressXP (for a detailed discussion of how prosodic prominence within a complement satisfie StressXP relative to a higher head selecting for that complement see Truckenbrodt 1995).

The convergence of all above models in predicting a pp-boundary after the raised NP of structure (20b) is not accidental. It is dictated by the need to capture the generalization that lexical maximal projections are always followed by a pp-boundary at their right edge (Nespor and Vogel 1986; Selkirk 1986, 2000; Ghini 1993; Truckenbrodt 1995, 1999). This generalization holds for Italian, too, and is well illustrated by the examples in (22) from Ghini (1993) and Frascarelli (2000) showing maximal projections in different clausal positions all triggering a pp-boundary at their right edge. Specificall, we have a subject DP in (22a); an object DP followed by an indirect object in (22b) and a postverbal subject in (22c); and finall a left-peripheral topic followed by a subject in (22d) (further examples are available in Nespor and Vogel 1986 and Frascarelli 2000). Insofar as we expect N-A sequences to follow the generalization illustrated in these examples and accounted for by the above models, the NP-raising structure in (20b) cannot constitute the syntactic representation underlying the single pp experimentally attested for N-A sequences. (In all examples syllables carrying word-level stress are underlined.)

verbs shows that they remain prosodically lexical and therefore subject to the constraints that govern the prosodic phrasing of lexical items even if they systematically raise to a higher functional head. Since the constraints on prosodic phrasing do not refer to lexical items themselves but to their projections, it follows that the projection of a lexical item raised to a functional empty head is viewed as lexical by the constraints for prosodic phrasing. The same does not apply to movement into the specifie of a functional head, where the head of the functional projection remains functional. See Samek-Lodovici (2005) for further discussion, as well as the discussion of example (23) later in this section. 
(22) a. (La verità) (vince).

the truth wins.3sg

'Truth wins.'

b. (Darò libri) (a Gianni).

(I) will-give. $1 \mathrm{sg}$ books to John

'I will give books to John.'

c. (Esamineranno il caso) (gli esperti).

Will-examine.3pl the case the experts

'The experts will examine the case.'

d. (a Gegé) (Paola) (gli parlerà) (domani).

To Gegé Paola to-him will-speak.3sg tomorrow

'As for Gegé, Paula will talk to him tomorrow.'

In contrast, joint prosodic phrasing of a head and its complement of the sort predicted to occur between N and AP under the N-raising structure (20a) is well attested and illustrated by the examples in (23) (see also Nespor and Vogel 1986; Ghini 1993; Frascarelli 2000). In (23a), a finit verb in $\mathrm{T}$ is phrased together with its object, while in (23b) a finit verb in $\mathrm{T}$ is phrased with a postverbal subject arguably stranded in specVP position.

(23) a. (Soffrirà [p:][e:]ne) (incredibilmente $\mathrm{d}[\mathrm{u}:] \mathrm{re}$ ).

(s/he) will-suffer.3sg affliction incredibly severe

'S/he will suffer extremely severe afflictions'

b. (Nuoterà Gianni).

Will-swim.3sg John

'John will swim.'

c. [TP V [VP DP tV $]]$

d. $\left[A g r P ~ N\left[F P A P t_{N}\left[N P t_{N}\right]\right]\right]$

The joint phrasing is highlighted by three phonological processes known to be impossible across pp-boundaries. The first known as 'raddoppiamento sintattico', lengthens the consonantal onset of a word whenever the previous word ends in a stressed syllable. The effect is visible on the lengthened [p:] onset of the noun pene in (23a) and attests the absence of a pp-boundary before the noun. The second process lengthens the syllable receiving the prosodic peak of the $\mathrm{pp}$, here determining the lengthened [e:] and [u:] in the nouns in (23a). The third process solves potential stress clashes by shifting the firs stress leftwards whenever a word with word-fina stress is followed by a word with word-initial stress. In sentences (23a) and (23b), the fina stress of the verb shifts to its firs syllable, shown in bold (the same process applies to 'Darò' in (22b)).

Sentence (23b) is particularly revealing because its underlying structure, shown in (23c), parallels the N-raising structure in (20a), repeated in (23d). The DP occurs in the specifie of the complement projection of the raised V much like AP does with respect to the raised $\mathrm{N}$. This structural parallelism guarantees that any model blind 
to categorial labeling that accounts for the shared pp in sentences like (23b) will also necessarily predict a shared pp for $\mathrm{N}$-A sequences derived via $\mathrm{N}$-raising.

Finally, note how the assumption that raising lexical heads make their target projections prosodically lexical is supported by the analysis of the examples in (23). Without this assumption, the finit verb raised to T would no longer count as prosodically lexical and consequently it would incorrectly be invisible to the prosodic constraints that phrase it with its complement.

The above discussion shows that the attested joint phrasing of $\mathrm{N}-\mathrm{A}$ sequences may only arise from the N-raising structure (20a), since the alternative NP-raising structure in (20b) determines two independent pps under every model of prosodic phrasing considered here. The only way to produce a single shared pp from the NPraising structure in (20b), repeated in (24) below, would be via a new constraint WrapFP forcing all items contained in a functional projection to be wrapped into a single pp. When applied to the empty functional projection AgrP the constraint would wrap NP and AP into one pp.

\section{(24) NP-raising: [AgrP NP $\left.\left.\mathrm{Agr}_{\mathrm{i} P \mathrm{AP}} \mathrm{F} \mathrm{t}_{\mathrm{i}}\right]\right]$}

There is however clear evidence against the existence of such a constraint. To begin with, Wrap-FP contradicts Truckenbrodt (1999), who showed that constraints on prosodic phrasing may not apply to functional projections headed by empty categories. ${ }^{9}$ Furthermore, a stipulation that Wrap-FP applies to DPs but not to clauserelated functional categories like TPs or CPs would also be required, making it an ad-hoc and uninformative solution. Without this stipulation Wrap-FP would incorrectly phrase the left-peripheral topic in (22d) with the rest of the sentence, since the topic lies in the specifie of the CP-level functional projection TopicP (Rizzi 1997). Likewise, the subject of the sentences in (25) lies either in the specifie of TP or, again, it constitutes a topic in TopicP, yet it cannot be phrased together with the following verb as required by Wrap-FP.
a. (la gabbia) (è già caduta).
(Nespor and Vogel 1986:170) the cage is already fallen
'The cage has already fallen.'
b. (Carlo) (ha portato) (tre bassotti) (alla mostra). (Frascarelli Carlo has brought three dachshunds to-the show 2000:19) 'Carl brought three dachshunds to the show.'

This undesirable ad-hoc restriction to DP-domains is fully general. The structural parallelism between the NP-raising structure in (24) and the structures for the sentences in (22) and (25) ensures that any structural constraint forcing NP and AP into

\footnotetext{
${ }^{9}$ We wish to thank an anonymous reviewer for reminding us about the relevance of Truckenbrodt's (1999) results. Truckenbrodt's Lexical Category Condition states that "constraints relating syntactic and prosodic categories apply to lexical syntactic elements and their projections, but not to functional elements and their projections, or to empty syntactic elements and their projections". The condition bans prosodic constraints from applying to projections of overt functional items as well as projections based on empty heads, whether lexical or functional. Truckenbrodt however does not consider hybrid cases where a lexical element raises into a higher functional head. As already mentioned we follow Samek-Lodovici (2005) in maintaining that in these cases the projection of the raised item counts as prosodically lexical.
} 
a single shared pp in (24) would also incorrectly impose a single pp on the initial topic and the rest of the sentence in (22d) and on the subject and the following verb in (25). Nor can this problem be solved via constraint-ranking under OT-analyses, since ranking is fi ed within a grammar and whatever ranking is necessary for the NP-raising structure carries over to (22) and (25).

We may thus confidentl conclude that the underlying syntactic structure of the $\mathrm{N}$-A sequences is the N-raising structure in (20a), repeated in (26). All major models of the prosody-syntax mapping unambiguously associate the attested phrasing of $\mathrm{N}$-A sequences with this structure. Furthermore, only this structure perfectly fit the empirical generalization holding of Italian syntax-prosody mapping.

\section{(26) N-raising: [AgrP $\left.\mathrm{N}\left[\mathrm{FP} A P t_{N}\left[\mathrm{NP}_{\mathrm{N}}\right]\right]\right]$}

Given such a convergence between theoretical and empirical observations we also conclude that the attested prosodic phrasing of $\mathrm{N}-\mathrm{A}$ sequences provides unequivocal evidence for the occurrence of $\mathrm{N}$-raising in Italian.

\subsection{Syntactic representation of A-N sequences}

Turning to A-N sequences, the joint ' $(\mathrm{A} \mathrm{N})$ ' phrasing attested in our experimental data may at firs appear surprising since the initial AP might appear to have to trigger a pp-boundary at its right edge. Once again we should consider the possible underlying representations in detail. The structure in (27a) occurs if $\mathrm{N}$ moves to the head of the functional projection hosting AP, while structure (27b) occurs if $\mathrm{N}$ does not move.

(27) a. N-raising: [FP AP N $\left.\left.\mathrm{N}_{\mathrm{i}}\left[\mathrm{NP} \mathrm{t}_{\mathrm{i}}\right]\right]\right]$

b. No raising: [FP AP F NP]

Structure (27b) is clearly inconsistent with the attested phrasing. This structure parallels the NP-raising structure discussed in the previous section, with a lexical XP in the specifie of a functional head that is not targeted by N-raising. In this case all models of syntax-prosody mapping predict a pp-boundary after the initial AP for the reasons already explained in the previous section. Since the expected boundary is absent, (27b) cannot be the correct representation.

The same models differ in their predictions with respect to (27a). Nespor and Vogel (1986), Selkirk (1986), and Ghini (1993) predict a post-AP boundary and therefore cannot account for the single pp found for A-N sequences. In Truckenbrodt's model, instead, the phrasing of (27a) depends on the ranking of Wrap-XP and AlignXP relative to each other as illustrated by Tableau 1 below. The raised $N$ makes the entire FP lexical as far as prosodic constraints are concerned. Wrap-XP therefore requires the entire FP to be contained in a single $\mathrm{pp}$. Consequently languages where Wrap-XP dominates AlignXP will phrase (27a) into a single pp even if this phrasing violates AlignXP. ${ }^{10}$ Note that the same is not true of (27b), where Wrap-XP

\footnotetext{
${ }^{10}$ The same analysis extends to Truckenbrodt's StressXP and AlignPP variant under the ranking $\{$ Wrap, AlignPP $\} \gg$ StressXP. The condition Wrap $\gg$ Stress XP ensures that (AP N) is parsed in a single pp as required by Wrap-XP even if $(A P)(N)$ would better satisfy StressXP by providing both items with their own pp-head. The condition AlignPP $\gg$ Stress XP in turn ensures that within (AP N) the pp-head falls rightmost
} 
only requires AP and NP to be each contained within a single pp but with no condition imposed on the entire FP. Even languages with the Wrap $\gg$ AlignXP ranking will therefore choose to satisfy AlignXP and place a boundary after AP as mentioned above.

\begin{tabular}{|l|c|c|}
\hline Tableau 1 & Wrap-XP & AlignXP \\
\hline$(\mathrm{AP} \mathrm{N})$ & $\checkmark$ & $*$ \\
\hline$(\mathrm{AP})(\mathrm{N})$ & $*$ & $\checkmark$ \\
\hline
\end{tabular}

If AP can be phrased with the following noun in (27a), why are the left-peripheral topics and subjects of the sentences in (22) above parsed in a pp of their own? The crucial difference lies in their syntactic representation. In (27a) AP occurs as the specifie of a projection headed by the raised N. As mentioned above, this makes the projection prosodically lexical and hence subject to Wrap-XP. The same is not true for the examples in (22). Consider for example sentence (22d), repeated as (28) below. The left-peripheral topic a Gegé lies in a TopicP projection at the top of the clause as shown in (28b). The head of TopicP is not fille by a lexical head. Consequently Wrap-XP places no condition on TopicP. The available trivial satisfaction of Wrap$\mathrm{XP}$ in turn enables the satisfaction of the lower ranked AlignXP, determining the pp-boundary immediately following the topic a Gegé.

(28) a. (a Gegé) (Paola) (gli parlerà) (domani).

to Gegé Paola to-him will-speak.3sg tomorrow

'As for Gegé, Paula will talk to him tomorrow.'

b. [TopicP [a Gegé $\left.]_{\mathrm{PP}} \operatorname{Topic}^{0}[\ldots]\right]$

The same analysis applies to the subject Paola in (28a) above and any other Italian preverbal subject provided they, too, are analyzed as located in the specifie of a higher projection not reached by raised finit verbs. While there are different views about the location of this projection (namely whether it is part of CP or the inflec tional field and also about the preverbal subjects that it hosts (i.e. whether they are base-generated and controlling a lower resumptive pro or raised all the way up from specVP), its existence is advocated by many of the scholars investigating preverbal subjects in null subject languages; see for example Barbosa (1995), Alexiadou and Anagnostopoulou (1998), Rizzi (2004), Cardinaletti (2004), Frascarelli (2007). For example, as noted by Alexiadou and Anagnostopoulou (1998) the higher position of overt subjects in languages like Italian follows immediately from the observation that they can be followed by a sentential adverb like probabilmente 'probably' (cf. (29a))

on $\mathrm{N}$ as attested despite the violation of StressXP on AP which is left without a pp-head. The opposite ranking would still predict a single pp (AP N) but by placing the pp-head on AP to satisfy StressXP (since $\mathrm{AP}$ is contained within the projection of $\mathrm{N}$, the pp-head on AP also counts as satisfying StressXP relative to N; see Truckenbrodt 1995 for a detailed discussion). The relevant competition is provided in the tableau below where the item carrying the pp-head is shown in bold.

\begin{tabular}{|c|c|c|c|}
\hline & Wrap-XP & AlignPP & StressXP \\
\hline$\sigma\left(\mathrm{AP} \quad \mathbf{N}_{\mathrm{i}}\right)$ & $\checkmark$ & $\checkmark$ & $*$ \\
\hline$\left(\mathbf{A P} \quad \mathrm{N}_{\mathrm{i}}\right)$ & $\checkmark$ & $*$ & $\checkmark$ \\
\hline$(\mathbf{A P})\left(\mathbf{N}_{\mathrm{i}}\right)$ & $*$ & $\checkmark$ & $\checkmark$ \\
\hline
\end{tabular}


or by an entire subordinate clause (cf. (29b)). This would be impossible if overt subjects were in a spec-head relation with the inflecte verb.

(29) a. Gianni probabilmente ha incontrato Maria.

John probably has met Mary

'Probably John has met Mary.'

b. I bambini se Maria viene andranno via.

The children if Mary comes will-go away

'If Mary comes the children will go away.'

The position of the above subjects on the other hand is accounted for if, as proposed for example in Frascarelli (2007), preverbal subjects are sentential topics sitting in a dedicated topic-related projection ShiftP (for 'aboutness-shift topic') from where they control a lower pro subject as shown in (30a) (adapted from Frascarelli; see also Barbosa 1995 and Alexiadou and Anagnostopoulou 1998). The analysis also correctly predicts that the same sentence will be ungrammatical in languages that lack null subjects (see for example sentence (30b) from French in Alexiadou and Anagnostopoulou 1998). It also find further support in prosodic studies which take the observed prevailing (SVO) phrasing in European Portuguese as opposed to (S)(VO) in Spanish (Elordieta et al. 2003; D'Imperio et al. 2005 among others) as evidence for a specIP position in European Portuguese and for a higher left-dislocated position of the subject in Spanish (Elordieta et al. 2005).

(30) a. [ShiftP Gianni $\mathrm{k}_{\mathrm{K}}$ [FP probabilmente [TP ha [vP $\operatorname{pro}_{\mathrm{k}}[\mathrm{vP}$ incontrato Maria]]]]]

b. *Jean probablement a rencontré Marie.

John probably has met Mary

'Probably John has met Mary.'

In conclusion, the single pp found for A-N sequences provides evidence for an $\mathrm{N}$-raising analysis where $\mathrm{N}$ moves into the head of the functional projection hosting AP in its specifie . It also supports Truckenbrodt's model of syntax-prosody mapping, as all other models incorrectly predict distinct pps for A and N. Finally, it provides further evidence for analyzing Italian referential preverbal subjects as located in a higher topic-related position dominating TP.

\section{Head and phrasal movement in DPs}

With respect to the debate on whether N-A order in Romance is due to N- or NPraising our results clearly support the former hypothesis for the reasons provided in the previous sections. It is natural to wonder to which degree this result is consistent with the available syntactic arguments for and against N-and NP-raising. As we will show, once closely examined, these arguments do not support a simple conclusion for or against N- or NP-movement. Arguments provided for either of the two analyses have often been reanalyzed as arguments for the opposite analysis. See for example the stranding of prepositional complements by a raising noun in $\langle\mathrm{N} A \mathrm{PP}\rangle$ sequences, proposed as evidence for N-raising in Cinque (1994) and Pereltsvaig (2006) but reanalyzed in terms of NP-raising in Cinque (2006); or the presence of N-raising in 
English, argued for in Kishimoto (2000) but rejected in Larson and Marušič (2004) and Cinque (2006). There also appears to be robust evidence for phrasal movement, but it appears to apply to functional projections above NP and its application to NP itself is far less obvious.

In this section we examine some of the most relevant evidence concerning the presence or absence of $\mathrm{N}$-movement in detail and eventually argue for an analysis of Italian DPs where phrasal movement of functional projections co-exists with strictly local N-raising. We start in 4.1 with a brief survey of the syntactic evidence supporting the availability of $\mathrm{N}$-raising, then move onto the syntactic evidence for phrasal movement and examine its compatibility with the $\mathrm{N}$-raising analysis advocated in the previous sections.

\subsection{Head movement}

The availability of $\mathrm{N}$-raising has been argued for in several independent studies and across many languages (e.g., Sproat and Shih 1991; Crisma 1991; Valois 1991; Bernstein 1991, 1993; Cinque 1994; Zamparelli 1995; Longobardi 1994, 2001, 2005; Kishimoto 2000; Rutkowski and Progovac 2006; Willis 2006; Pereltsvaig 2006; Artiagoitia 2006). While evidence based on word order alone cannot distinguish between N- and NP-raising, direct interaction of the raising noun with higher syntactic heads provides the clearest possible syntactic evidence for the existence of N-raising. This interaction may occur in three different ways: (i) replacement of a higher head $\mathrm{H}$ with $\mathrm{N}$, yielding a complementary distribution between $\mathrm{H}$ and $\mathrm{N}$; (ii) incorporation of $\mathrm{N}$ into a higher head $\mathrm{H}$, with $\mathrm{H}$ emerging as an affi of $\mathrm{N}$; (iii) blocking of $\mathrm{N}$-raising by a higher head intervening in the path of N. Below we describe an instance of each of the above cases but further instances are available in the literature cited above.

Head-replacement is well illustrated by Longobardi's studies of N-to-D movement, which also provide some of the strongest possible evidence for the availability of N-raising in Italian (Longobardi 1994, 1996, 2001, 2005). Longobardi notices that whenever a determiner is present, a proper name $\mathrm{N}$ occurring with possessives or with focusing adjectives like solo (only) must follow the adjective, see (31a) and (31b). Yet the same noun may precede the adjective by raising to $D$, see (31c). Note that a determiner must be present whenever $N$ does not move, as shown in (31d), supporting the N-to-D analysis of (31c) (all examples from Longobardi 2001. For additional examples across distinct languages see Longobardi 2001 and references listed there).

(31) a. La sola Napoli (è stata prescelta tra le città italiane). the only Naples (is been chosen among the cities Italian) 'Only Naples was selected among Italian cities.'

b. * La Napoli sola (è stata prescelta tra le città italiane).

c. Napoli sola (è stata prescelta tra le città italiane).

d. * Sola Napoli (è stata prescelta tra le città italiane).

As Longobardi remarks, N-to-D raising immediately explains the complementary distribution of $\mathrm{N}$ and overt $\mathrm{D}$ in DP-initial position. The same is not true for NPraising since NP would move to specDP and thus allow for the occurrence of D to 
its right. Longobardi's analysis is more complex and informative than we can expose here, identifying for example the conditions that determine whether $\mathrm{N}$-to-D raising is or is not available to specifi classes of nouns. What is relevant in the context of this study is that it shows that N-raising can occur in Italian DPs, providing independent support for the $\mathrm{N}$-raising analysis of $\mathrm{N}-\mathrm{A}$ sequences advocated in this paper.

Further evidence for $\mathrm{N}$-raising comes from cases where a raising noun incorporates into $\mathrm{D}$, with $\mathrm{D}$ surfacing as a suffi of the noun. This is best illustrated by Scandinavian languages, including the Danish examples in (32a) below where the determiner en emerges as a suffi of the raised noun hest 'horse' (Delsing 1993; Embick and Noyer 2001). The original post-determiner position of the noun is visible in (32b), where N-raising is blocked by the intervening adjective røde 'red'.

(32) a. hest-en

horse.def

'the horse'

b. den røde hest

def red horse

'the red horse'

The third type of interaction, N-raising blocked by an intervening head, is already illustrated by the above Danish data. "An interesting case is also examined in Pereltsvaig's (2006) analysis of Russian approximative inversion (but see also her discussion of Hebrew and Artiagoitia's 2006 discussion of Basque). As (33) shows, a noun raising to the left of its numeral specificatio determines an approximative interpretation of the numeral. Following Bailyn (2004), Pereltsvaig maintains that the numeral occurs in the specifie of a higher NumP projection when assigned genitive case but in the head of the same projection when assigned instrumental case. Correspondingly, N-raising to the even higher projection associated with the approximative interpretation is possible under genitive case but not instrumental case, where the intervening overt Num head blocks N-raising; see the examples in (33) and (34) from Pereltsvaig (2006).

(33) a. desjat' kardinalov

ten cardinals

'Ten cardinals'

b. kardinalov desjat'

cardinals ten

'Approximately ten cardinals'

(34) a. Džejms Bond vypil rjumok desjat' vodki.

James Bond drank-up glasses.GEN ten vodka.GEN

'James Bond drank up approximately ten glasses of vodka.'

\footnotetext{
${ }^{11}$ The fact that in the above data N-raising is blocked by intervening adjectives might support a view of adjectives as heading projections that are a direct part of the main spine of the DP structure as in Artiagoitia (2006). The same analysis however does not apply to languages like Italian where adjectives show no corresponding blocking effects.
} 
b. * Džejms Bond napilsja rjumkami desjat'ju vodki. James Bond got-drunk glasses.INSTR ten.INSTR vodka.GEN 'James Bond got drunk from approximately ten glasses of vodka.'

In conclusion, there is substantive independent syntactic evidence for N-raising in both Italian and other languages. As discussed in the next section, this does not exclude the presence of phrasal movement within Italian DPs but neither is the presence of phrasal movement sufficien to exclude $\mathrm{N}$-raising.

\subsection{Phrasal movement}

The evidence for DP-internal phrasal movement is compelling, see among others Laenzlinger (2000), Knittel (2005), and Cinque (2005, 2006). Here we examine Cinque's 2005 and 2006 studies because we fin them particularly informative and also because they explicitly argue against $\mathrm{N}$-movement. We show that while they provide clear evidence for the occurrence of phrasal movement in Italian DPs, on close inspection they do not exclude the $\mathrm{N}$-raising analysis found necessary for the adjectives and nouns tested in our experiment.

As mentioned, Cinque (2005) convincingly argues for a universal merge order $<$ Dem \# A N $>$. His study also examines what movement restrictions are necessary to prevent the derivation of unattested orders reaching two important conclusions. The firs one is that remnant movement must be disallowed. If this were not the case unattested orders would become derivable. For example, the impossible $\langle$ Dem A \# N $>$ order becomes derivable as shown in (35) by firs raising N or NP to the left of A and then moving the remnant FP containing the adjective to the left of \#. Moved constituents are shown in square brackets.

$$
<\operatorname{Dem} \# \mathrm{~A} \mathrm{~N}>\rightarrow<\operatorname{Dem} \#[\mathrm{~N}] \mathrm{A} \mathrm{t}_{\mathrm{N}}>\rightarrow<\operatorname{Dem}\left[\mathrm{FP} A t_{\mathrm{N}}\right] \# \mathrm{~N} \mathrm{t}>
$$

The second conclusion concerns the necessity of pied-piping in order to derive those attested orders that seem to defy the universal $<$ Dem \# A N $>$ hierarchy (see also Shlonsky 2004). For example, as (36a) shows the order $<\mathrm{N}$ A \# Dem $>$ can be derived by pied-piping the complement of the projection hosting the raised noun (i.e., piedpiping of the whose picture type in Cinque's terminology), while (36b) shows how the order $<$ \# N A Dem $>$ follows from pied-piping the projection immediately above the raising noun (pied-piping of the picture of who type). In contrast, no amount of pied-piping will ever derive orders that require a different initial merge-order. For example, the impossible $<$ Dem A \# N $>$ or $<\# \mathrm{~N}$ Dem $\mathrm{A}>$ would respectively require merging $A$ before \# in one case and merging \# before Dem in the other. Given these restrictions, the ten universally unattested orders can be characterized as those that defy the $<$ Dem \# A N $>$ hierarchy while remaining underivable via movement of the noun (whether as N or NP) and pied-piping (Cinque 2005).

(36) a. $<$ Dem \# A N $\rightarrow<$ Dem \# [N] A $>\rightarrow<$ Dem [N A] \# $>$

$$
\text { b. } \quad \begin{aligned}
<\operatorname{Dem} \# \text { A N }>\rightarrow<\operatorname{Dem} \#[N] A>\rightarrow & \rightarrow<[\text { [N [N] A] Dem }>
\end{aligned}
$$

Cinque's analysis provides strong evidence for phrasal movement, since without it pied-piping could not occur and several attested orders would be incorrectly predicted to be impossible. Cinque, however, also claims N-movement to be impossible. 
This claim is made in the context of a more general theoretical goal aiming at keeping all syntactic movement phrasal. Yet we could not fin any specifi evidence directly linking $\mathrm{N}$-movement to the derivation of one of the unattested orders (a similar conclusion is reached in Artiagoitia 2006:22). ${ }^{12}$ As far as we can see, all instances of $\mathrm{NP}$-movements proposed by Cinque can be recast in terms of $\mathrm{N}$-movement with no analytical loss but for the theoretical goal mentioned above. For example, nothing prevents the orders $<$ Dem \# [N] A $>$, $<$ Dem $[N] \# A>$, and $<[N]$ Dem \# $A>$ derived via NP-movement by Cinque from being reanalyzed as derived by $\mathrm{N}$-movement. Nor does $\mathrm{N}$-movement enable the derivation of any of the unattested orders, provided remnant movement remains banned. All in all, while keeping all movement phrasal might be theoretically desirable, the case against $\mathrm{N}$-movement is not empirically supported. The evidence for $\mathrm{N}$-raising presented in the previous sections and the evidence for phrasal movement in Cinque's research instead suggest that DP-internal phrasal and head-movement might co-exist, with phrasal movement affecting functional projections and head-movement restricted to $\mathrm{N}$-raising.

Cinque (2006) further refine the argument for DP-internal phrasal movement by arguing for its obligatoriness in Italian. In an impressive comparative study of the distribution of nouns and adjectives in English and Italian Cinque shows that these languages differ in the distribution of direct and indirect modificatio adjectives as shown in (37)..$^{13}$

(37) a. Italian: Direct Mod. $>\mathbf{N}>$ Direct Mod. $>$ Indirect Mod.

b. English: Indirect Mod. $>$ Direct Mod. $>\mathbf{N}>$ Indirect Mod.

As Cinque points out, these distributions suggest that the two adjectival classes are merged in distinct positions within the DP. Yet, Cinque notes, it is impossible to posit a universal merge order while at the same time deriving the above distributions via $\mathrm{N}$-movement alone. For example, the universal hierarchy in (38a) is incompatible with Italian because movement of $\mathrm{N}$ into the middle position yields the incorrect distribution of pre- and post-nominal adjectival classes, while movement into the leftmost position yields the incorrect order for post-nominal classes. The alternative hierarchy in (38b) in turn is incompatible with English because the order for prenominal classes becomes underivable with or without $\mathrm{N}$-movement.

(38) a. Indirect Mod. $>$ Direct Mod. $>\mathbf{N}$

b. Direct Mod. $>$ Indirect Mod. $>\mathbf{N}$

This impasse provides Cinque with a persuasive argument in support of phrasal movement in Italian. Assuming (38a) as the universal merge order, the Italian distri-

\footnotetext{
${ }^{12}$ Many of the claims against $\mathrm{N}$-movement in Cinque (2005) reject it in combination with remnant movement. As such these claims are of course correct but the problem in these cases is remnant movement itself, which gives rise to incorrect predictions even in absence of $\mathrm{N}$-movement (as also noticed by Cinque 2005:324; fn.30). In a recent personal communication, Cinque agreed that the main argument favoring NPmovement over $\mathrm{N}$-movement is conceptual, related to the goal of keeping all movement phrasal. He also noted that under $\mathrm{N}$-movement the impossibility of remnant movement must be stipulated, whereas under NP-movement it can be derived from Kayne's (2005) closeness driven movement analysis (see Cinque 2005:326).

${ }^{13} \mathrm{~A}$ brief description of the properties distinguishing direct and indirect modificatio adjectives is provided in footnote 1. See also Sproat and Shih (1991), Alexiadou (2001), Knittel (2005), Cinque (2006) among others.
} 
bution is reached as shown in (39) and (40) below by obligatorily moving the lower section of the DP containing the direct modificatio adjectives (i.e., FP3) to the left of the phrase containing the indirect modificatio adjectives (i.e., FP2). The NP itself may or may not move to the left of the direct modificatio adjectives. ${ }^{14}$ If it remains in situ the fina order is $<$ Dir.Mod N Ind.Mod $>$, see (39). If it moves, the fina order becomes $<$ N Dir.Mod Ind.Mod. $>$, see (40). Crucially, in both cases the fina structure matches the attested distribution of Italian adjectives in (37a).

(39)

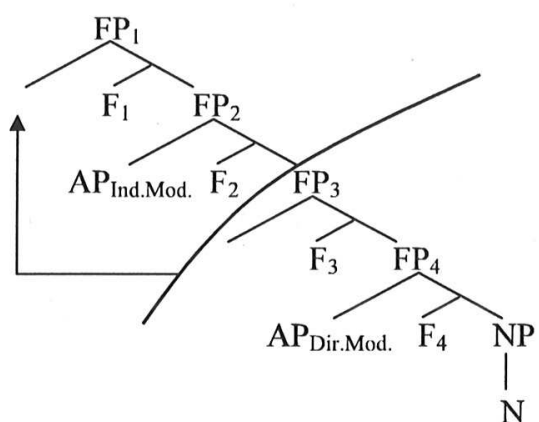

(40)

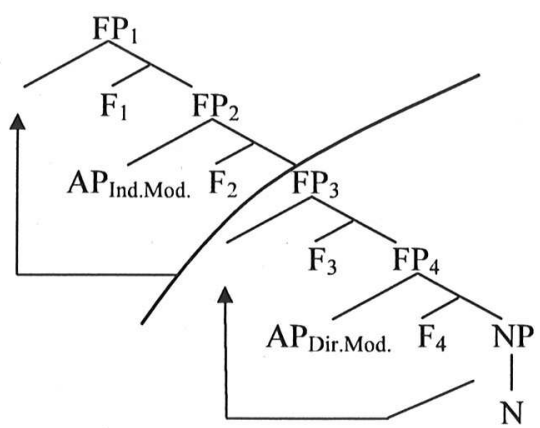

Once again Cinque's analysis provides strong evidence for the presence of phrasal movement of functional projections within Italian DPs but does not provide direct evidence against $\mathrm{N}$-movement with respect to adjectives of direct modification Cinque's observation that unbounded $\mathrm{N}$-movement determines the incorrect order $<\mathrm{N}$ Ind.Mod Dir.Mod $>$ also applies to unbounded NP-movement (for example NPraising to specFP3 followed by NP-movement to specFP1 while assuming no FP3 movement). What Cinque's study truly shows is that nouns cannot raise above indirect modificatio adjectives, whether via N- or NP-movement. Within the lower section of the DP, however, N-raising remains a viable hypothesis. ${ }^{15}$

\footnotetext{
${ }^{14}$ Whether movement past direct modificatio adjectives occurs or not also depends on the particular subclass of adjectives. Cinque (2006) notes that movement is obligatory with classificator and provenance/nationality adjectives but optional with higher direct modificatio adjectives of color, shape, size value, etc.

${ }^{15}$ Cinque's results also raise the issue of the location of $\mathrm{D}$ in view of Longobardi's N-to-D raising. One possibility is that $\mathrm{D}$ in Italian is merged immediately above FP3; see for example the hypothesis allowing for the existence of an indefinit determiner projection in this position in Cinque (2006).
} 


\subsection{A combined analysis of $\mathrm{N}-$ and phrasal raising for Italian DPs}

Is it possible to simultaneously derive Cinque's results on phrasal movement and the head-raising representation shown necessary in the previous sections? One possibility is to combine the two analyses and maintain a representation of Italian DPs like (40) above where $\mathrm{N}$ raises as a head to F4 and optionally to F3, as required by the attested prosodic phrasing of $\mathrm{N}-\mathrm{A}$ and $\mathrm{A}-\mathrm{N}$ sequences, but never beyond $\mathrm{F} 3$, as required by Cinque's analysis of Italian adjectives. As Cinque notices, once movement is restricted in this way only direct modificatio adjectives can occur in both the N$\mathrm{A}$ and A-N orders whereas indirect modificatio adjectives necessarily follow the noun. This is a welcome result as it explains why symmetric $\mathrm{N}-\mathrm{A}$ and $\mathrm{A}-\mathrm{N}$ sequences necessarily involve direct modificatio adjectives.

As for why N-raising co-exists with phrasal raising of higher functional projections, a possible answer is suggested by Cinque's (2005) proposal that DP-internal movement is subject to a version of Kayne's constraint on remnant movement (Kayne 2005:54). Kayne's constraint restricts the set of syntactic items that can legitimately move to the specifie of a head $\mathrm{H}$ to the closest category distinct from the complement of $\mathrm{H}$. Under a bare-structure representation à la Chomsky (1995) the noun of the simple N-A and A-N sequences examined in our experiment would simultaneously count as head and maximal projection. Raising the noun as a head would form a shorter chain and thus be preferable to phrasal movement on economy considerations, explaining the occurrence of $\mathrm{N}$-raising. The same choice, however, is not available to higher functional projections because they necessarily involve a complement and therefore count as phrasal, explaining Cinque's finding on the phrasal movement of higher functional projections.

The proposed combined analysis also makes fine-graine predictions that could potentially highlight subtle syntactic differences not easily testable with syntactic means alone but potentially revealed by prosodic phrasing. The firs prediction concerns N-A sequences involving unambiguous indirect modificatio adjectives. Following Cinque (2006), the combined analysis assigns to them a structure similar to (41a) below, where AP is preceded by an entire NP encapsulated within the raising FP3 projection. Consequently N and A would be predicted to occur in two separate pps, since NP triggers a pp-boundary to its right. We thus expect the structural difference between $\mathrm{N}-\mathrm{A}$ sequences involving direct modificatio adjectives, based on N-raising, and sequences involving indirect modificatio adjectives, formed via phrasal raising, to be reflecte in their prosodic phrasing. For example, insofar as past-participle based reduced relative clauses share the syntactic properties of indirect modificatio adjectives, as suggested in Cinque (2006) on the basis of their obligatory post-nominal distribution, a pp-boundary should intervene between the noun and the past-participle modifie rotta 'broken' in (41b) below. If borne out, this prediction would at once provide significan support for Cinque's analysis as well as for the $\mathrm{N}$-raising representation for $\mathrm{N}-\mathrm{A}$ and $\mathrm{A}-\mathrm{N}$ sequences advocated here.

(41) a. [FP1 [FP3 F3 [FP4 F4 NP ] ] $\left.\mathrm{F}_{1} \quad\left[\mathrm{FP} 2 \mathrm{AP} \mathrm{F}_{2} \mathrm{t}_{\mathrm{i}}\right]\right]$

b. una porta rotta

a door broken

'a broken door' 
The second prediction concerns the analysis of expressions like (42) below adapted from Cinque (1994) where an adjective intervenes between a noun and its complement.

(42) l' invasione brutale di Parigi

the invasion brutal of Paris

'the brutal invasion of Paris'

There are two possible structural analyses of (42). The more traditional one, proposed in Cinque (1994) and reconsidered in Pereltsvaig (2006), maintains that the noun raises above the adjective as a head, stranding its prepositional complement behind as shown in (43). This analysis is inconsistent with Kayne's remnant movement constraint which would require the entire NP to move to specFP3, PP-complement included.

\section{(43) $\left[\mathrm{FP}_{3} \mathrm{~N}_{\mathrm{i}}\left[\mathrm{FP} 4 \mathrm{AP} \mathrm{F}_{4}\left[\mathrm{NP} \mathrm{t}_{\mathrm{i}} \mathrm{PP}\right]\right]\right]$}

Cinque (2006) proposes an alternative analysis based on Kayne (1999, 2000, 2002) where the preposition $d i$ 'of' introducing the complement is supplied at the top of the DP and the complement of the noun moves to get case leaving the noun able to raise as a complement-free NP. The main derivational steps are shown in (44). Stage (i) provides the initial configuration Stage (ii) follows from merge of K(ase) and attraction of the complement DP to its specifie. Stage (iii) follows from merge of the preposition $d i$ 'of' at the top of the structure and the attraction of the remnant $l a$ brutale invasione (the brutal invasion). Stage (iv) follows from raising the entire NP above the adjective.

(44) i. [la [brutale [invasione [Parigi]]]]

ii. $\quad\left[[\text { Parigi }]_{\mathrm{k}} \mathrm{K}\right.$ [la [brutale [invasione $\left.\left.\left.\left.\mathfrak{t}_{\mathrm{k}}\right]\right]\right]\right]$

iii. [[la [brutale [invasione $\mathrm{t}]]]_{\mathrm{s}} \mathrm{di}\left[[\right.$ Parigi $\left.\left.] \mathrm{K} \mathrm{t}_{\mathrm{s}}\right]\right]$

iv. $\quad\left[\left[\right.\right.$ la $\left[[\text { invasione } t]_{i}\left[\text { brutale } \mathrm{t}_{\mathrm{i}}\right]\right]_{\mathrm{s}}$ di $\left[[\right.$ Parigi $\left.\left.\left.] \mathrm{K}_{\mathrm{s}}\right]\right]\right]$

Once again the two analyses predict a distinct prosodic phrasing of the resulting N-A sequence. The analysis of Cinque (1994) predicts a joint pp, whereas the Kaynian analysis in Cinque (2006) predicts two distinct pps, because the raised NP would trigger a pp-boundary at its right edge. If borne out, the latter prediction would thus provide at once evidence for the NP-raising analysis argued for in Cinque (2006) as well as new independent support for Kayne's model of syntactic derivations.

\section{Conclusions}

The robust generalizations available on Italian prosodic phrasing and current models of the syntax-prosody mapping converge in dictating an $\mathrm{N}$-raising analysis for simple $\mathrm{N}-\mathrm{A}$ and $\mathrm{A}-\mathrm{N}$ sequences involving adjectives of direct modification An alternative analysis based on NP-raising would directly contradict the joint phrasing that emerged from our experimental study, as well as current understanding of how prosodic phrasing is determined in Italian and other languages. 
This result was shown to have important syntactic and prosodic implications. From a prosodic perspective, it lends support to Truckenbrodt's model of the syntaxprosody mapping, which alone among the models examined here can predict the joint prosodic phrasing of both $\mathrm{N}-\mathrm{A}$ and $\mathrm{A}-\mathrm{N}$ sequences. From a syntactic perspective, we showed that the $\mathrm{N}$-raising analysis is consistent with the equally necessary phrasal movement discussed in Cinque (2005, 2006). What emerges is a complex model of Italian DPs where limited, local, N-raising co-exists with phrasal movement of higher functional projections. Furthermore the occurrence of N- vs. NP-raising was shown to be potentially determined by the type of items contained in the DP itself, depending for example on the class of adjectives preceding or following the noun as well as the presence of a complement of the noun.

We also showed how prosodic phrasing can test and determine fine-graine properties of syntactic analysis that range from the syntactic representation of Italian overt subjects and complex DPs to the precise conditions constraining movement in UG and the distinct available models of syntactic derivations.

Acknowledgements The experiment described in this paper was presented at the $1^{\text {st }}$ Prosody-Syntax Interface Workshop at University College London in October 2006 and we would like to thank all the participants for the lively discussion. We are particularly grateful to Guglielmo Cinque, Laura Downing, Brechtje Post, Lisa Selkirk and the audiences at the Workshop on Nominalizations across Languages (University of Stuttgart, 29 Nov-1 Dec 2007) and the $2^{\text {nd }}$ Prosody-Syntax Interface Workshop (ZAS, 1314 June 2008) for discussion of and comments on aspects of the work presented here, as well as to the anonymous reviewers of NLLT for their useful remarks and questions. Special thanks go to Sam Hellmuth and Malte Zimmermann for their efficien help with findin informants in the Berlin/Potsdam area, and to all the participants of the experimental study.

\section{Appendix: Experimental materials}

The experimental sentences are listed below. The adjectives and nouns forming the relevant $\mathrm{N}-\mathrm{A}$ and $\mathrm{A}-\mathrm{N}$ sequences are shown in bold, with the measured fina and stressed syllables in capitals. Word stress always falls on the antepenultimate syllable except for the adjective tipico, where it falls on the initial syllable.

- [A N $]_{\text {Subj }}$ V Obj

1. Un po.TEN.TE pre.LA.TO può imporre il suo punto di vista anche al papa. a powerful prelate can impose the his point of view even to-the pope

2. Un pro.VET.TO ten.NIS.TA dovrebbe evitare un errore così plateale. an experienced tennis-player should avoid a mistake so evident

3. Un TI.pi.CO pre.TES.TO comporta il dichiararsi malati anche se in ottima A typical excuse involves the self-declaring sick even if in optimal salute. health

4. Un BRUT.TO POR.TO diminuirebbe il valore turistico della nostra città. An ugly harbor would-lower the value tourist of-the our town

5. Un cor.RET.TO con.TAT.TO determina l' accensione della spia verde. A correct contact determines the switching-on of the light green 
- [N A ]Subj V Obj

1. Un pre.LA.TO po.TEN.TE può imporre il suo punto di vista anche al papa. a prelate powerful can impose the his point of view even to-the pope

2. Un ten.NIS.TA pro.VET.TO dovrebbe evitare un errore così plateale. a tennis-player experienced should avoid a mistake so evident

3. Un pre.TES.TO TI.pi.CO comporta il dichiararsi malati anche se in ottima an excuse typical involves the self-declaring sick even if in optimal salute. health

4. Un POR.TO BRUT.TO diminuirebbe il valore turistico della nostra città. an harbor ugly would-lower the value tourist of-the our town

5. Un con.TAT.TO cor.RET.TO determina l' accensione della spia verde. a contact correct determines the switching-on of the light green

- Subj V [A N] obj X

1. Abbiamo contattato un po.TEN.TE pre.LA.TO con il permesso del papa. (we) have contacted a powerful prelate with the permission of-the pope

2. Abbiamo bisogno di un pro.VET.TO ten.NIS.TA per la squadra olimpica. (we) have need of an experienced tennis-player for the team Olympic

3. Gli studenti hanno usato un TI.pi.CO pre.TES.TO con pessimi risultati. the students have used a typical excuse with terrible results

4. Vorremmo evitare un BRUT.TO POR.TO proprio al centro della città. (we) would-like to-avoid an ugly harbor right at-the centre of-the town

5. Le componenti elettriche devono stabilire un cor.RET.TO con.TAT.TO prima the components electric must establish a correct contact before di ogni accensione. of every switching-on

- Subj V [N A $]_{\text {obj }} X$

1. Abbiamo contattato un pre.LA.TO po.TEN.TE con il permesso del papa. (we) have contacted a powerful prelate with the permission of-the pope

2. Abbiamo bisogno di un ten.NIS.TA pro.VET.TO per la squadra olimpica. (we) have need of a tennis-player experienced for the team Olympic

3. Gli studenti hanno usato un pre.TES.TO TI.pi.CO con pessimi risultati. the students have used an excuse typical with terrible results

4. Vorremmo evitare un POR.TO BRUT.TO proprio al centro della città. (we) would-like to-avoid a harbor ugly right at-the centre of-the town

5. Le componenti elettriche devono stabilire un con.TAT.TO cor.RET.TO the components electric must establish a contact correct 
prima di ogni accensione.

before of every switching-on

\section{References}

Abels, Klaus, and Ad Neeleman. 2006. Universal 20 without the LCA. Manuscript, University College London.

Abney, Steven. 1987. The English Noun Phrase in its sentential aspect. Doctoral dissertation, MIT.

Alexiadou, Artemis. 2001. Adjective syntax and noun raising: word order asymmetries in the DP as the result of adjective distribution. Studia Linguistica 55: 217-248.

Alexiadou, Artemis, and Elena Anagnostopoulou. 1998. Parametrizing AGR: word order, V-movement and EPP checking. Natural Language and Linguistic Theory 16: 491-539.

Artiagoitia, Xabier. 2006. Basque adjectives and the functional structure of the noun phrase. Manuscript, University of the Basque Country.

Bailyn, John F. 2004. The case of Q. In Proceedings of FASL 12: the Ottawa meeting, eds. Olga Arnaudova Wayles Browne, María Luisa Rivero, and Danijela Stojanovic, 1-35. Ann Arbor: Michigan Slavic Publications.

Barbosa, Maria do Pilar Pereira. 1995. Null subjects. Doctoral dissertation, MIT

Beckman, Mary, and Jan Edwards. 1987. The phonological domains of fina lengthening. Journal of the Acoustical Society of America 81(S1): S67.

Beckman, Mary, and Jan Edwards. 1990. Lengthenings and shortenings and the nature of prosodic constituency. In Between the grammar and physics of speech, papers in laboratory phonology I, eds. John Kingston and Mary Beckman, 152-178. Cambridge: Cambridge University Press.

Beckman, Mary, and Jan Edwards. 1991. Prosodic categories and duration control. Journal of the Acoustical Society of America 89(4B): 1869

Bernstein, Judy. 1991. DPs in French and Walloon: evidence for parametric variation nominal head movement. Probus 3: 101-126.

Bernstein, Judy. 1993. Topics in the syntax of nominal structure across Romance. Doctoral dissertation, CUNY.

Bhattacharya, Tanmoy. 1998. Kinship inversion in Bangla. Papers in Linguistics from the University of Manchester (PLUM) 7: 143-156.

Boersma, Paul. 2001. PrAAT, a system for doing phonetics by computer. Glot International 5: 341-345

Boersma, Paul, and David Weenink. 2008. Praat: doing phonetics by computer (Version 5.0.06; Computer program). http://www.praat.org. Accessed 28 November 2008.

Cardinaletti, Anna. 2004. Towards a cartography of subject positions. In The cartography of syntactic structures, ed. Luigi Rizzi, Vol. 2 of The structure of CP and IP, 115-165. Oxford: Oxford University Press.

Chomsky, Noam. 1995. Bare phrase structure. In Government and binding theory and the minimalist program, ed. Gert Webelhuth, 383-439. Oxford: Blackwell.

Cinque, Guglielmo. 1994. On the evidence for partial N movement in the Romance DP. In Paths towards universal grammar, eds. Guglielmo Cinque, Jan Koster, Jean-Yves Pollock, Luigi Rizzi, and Raffaella Zanuttini, 85-110. Georgetown: Georgetown University Press.

Cinque, Guglielmo. 2005. Deriving Greenberg's Universal 20 and its exceptions. Linguistic Inquiry 36: $315-332$.

Cinque, Guglielmo. 2006. The dual source of adjectives and phrasal movement in the Romance DP. Manuscript, University of Venice.

Crisma, Paola. 1991. Functional categories inside the noun phrase: A study on the distribution of nominal modifiers BA Thesis, University of Venice.

Crisma, Paola. 1993. On adjective placement in Romance and Germanic event nominals. Rivista di Grammatica Generativa 18: 61-100.

Cruttenden, Alan. 1997. Intonation, 2nd edn. Cambridge: Cambridge University Press.

Delsing, Lars-Olof. 1993. The internal structure of noun phrases in the Scandinavian languages. Doctoral Dissertation, University of Lund.

D’Imperio, Mariapaola, Gorka Elordieta, Sónia Frota, Pilar Prieto, and Marina Vigário. 2005. Intonational phrasing in Romance: the role of syntactic and prosodic structure. In Prosodies-With special reference to Iberian languages, eds. Sónia Frota, Marina Vigário, and Maria J. Freitas, 59-97. Berlin \& New York: Mouton de Gruyter. 
Edwards, Jan, and Mary Beckman. 1988. Articulatory timing and the prosodic interpretation of syllable duration. Phonetica 45: 156-174.

Elordieta, Gorka, Sónia Frota, Pilar Prieto, and Marina Vigário. 2003. Effects of constituent weight and syntactic branching on intonational phrasing in Ibero-Romance. In Proceedings of the 15th international congress of phonetic sciences, ed. María-Josep Solé, Daniel Recasens, and Joaquin Romero, 487-490.

Elordieta, Gorka, Sónia Frota, and Marina Vigário. 2005. Subjects, objects and intonational phrasing in Spanish and Portuguese. Studia Linguistica 59: 110-143.

Embick, David, and Rolf Noyer. 2001. Movement operations after syntax. Linguistic Inquiry 32: 555-595.

Frascarelli, Mara. 2000. The syntax-phonology interface in focus and topic constructions in Italian. In Studies in natural language and linguistic theory, Vol. 50. Dordrecht: Kluwer

Frascarelli, Mara. 2007. Subjects, topics and the interpretation of referential pro. An interface approach to the linking of (null) pronouns. Natural Language and Linguistics Theory 25: 691-734.

Frota, Sónia, Mariapaola D’Imperio, Gorka Elordieta, Pilar Prieto, and Marina Vigário. 2007. The phonetics and phonology of intonational phrasing in Romance. In Segmental and prosodic issues in Romance phonology, eds. Pilar Prieto, Joan Mascaró, and Maria-Josep Solé, 131-153. Amsterdam: John Benjamins

Ghini, Mirco. 1993. Phi-formation in Italian: a new proposal. Toronto Working Papers in Linguistics 12: 41-78.

Grice, Martine, Mariapaola D'Imperio, Michelina Savino, and Cinzia Avesani. 2005. Strategies for intonation labelling across varieties of Italian. In Prosodic typology: the phonology of intonation and phrasing, ed. Sun-Ah Jun, 362-389. Oxford: Oxford University Press.

Halle, Morris, and Jean-Roger Vergnaud. 1987. An essay on stress. Cambridge: MIT Press.

Hammond, Michael. 1984. Constraining metrical theory: a modular theory of rhythm and destressing. Doctoral dissertation, University of California.

Hayes, Bruce. 1988. Final lengthening and the prosodic hierarchy. Journal of the Acoustical Society of America 84: S97.

Hayes, Bruce. 1995. Metrical stress theory. Chicago: University of Chicago Press.

Hellmuth, Sam. 2004. Prosodic weight and phonological phrasing in Cairene Arabic. In Proceedings of annual meeting of Chicago Linguistic Society, Vol. 40, 97-111.

Kayne, Richard S. 1999. Prepositional complementizers as attractors. Probus 11: 39-73.

Kayne, Richard S. 2000. A note on prepositions, complementizers, and word order universals. In Parameters and universals, eds. Richard S. Kayne, 314-326. Oxford: Oxford University Press.

Kayne, Richard S. 2002. On some prepositions that look DP-internal: English of and French de. Catalan Journal of Linguistics 1: 71-115.

Kayne, Richard S. 2005. Some notes on comparative syntax, with special reference to English and French. In The Oxford handbook of comparative syntax, eds. Guglielmo Cinque and S. Richard Kayne, 3-69. Oxford: Oxford University Press.

Kishimoto, Hideki. 2000. Indefinit pronouns and overt N-raising. Linguistic Inquiry 31: 557-566.

Knittel, Marie Laurence. 2005. Some remarks on adjective placement in the French NP. Probus 17: 185226.

Laenzlinger, Christopher. 2000. French adjective ordering: perspective on DP-internal movement types. Generative Grammar in Geneva 1: 55-104.

Larson, Richard K., and Franc Marušič. 2004. On indefinit pronoun structures with APs: Reply to Kishimoto. Linguistic Inquiry 35: 268-287.

Longobardi, Giuseppe. 1994. Reference and proper names: a theory of N-movement in syntax and logical form. Linguistic Inquiry 25: 609-665.

Longobardi, Giuseppe 1996. The syntax of N-raising: A minimalist theory. In OTS working papers in theoretical linguistics. Utrecht: University of Utrecht, Utrecht Institute of Linguistics.

Longobardi, Giuseppe. 2001. The structure of DPs: some principles, parameters and problems. In The handbook of contemporary syntactic theory, eds. Mark Baltin and Chris Collins, 562-601. Oxford: Blackwell.

Longobardi, Giuseppe. 2005. Toward a unifie grammar of reference. Zeitschrift für Sprachwissenschaft 24: 5-44.

McCarthy, John, and Alan Prince. 1993. Generalized alignment. In Yearbook of morphology 1993, eds. Geert Booij and Jaap van Marle, 79-153. Dordrecht: Kluwer.

Nespor, Marina, and Irene Vogel. 1986. Prosodic phonology. Dordrecht: Foris. 
Pereltsvaig, Asya. 2006. Passing by cardinals: in support of head movement in nominals. In Formal approaches to Slavic linguistics 14: the Princeton meeting, eds. James Lavine, Steven Franks, Mila Tasseva-Kurktchieva, and Hana Filip, 277-292. Ann Arbor: Slavic Publications.

Post, Brechtje. 2000. Tonal and phrasal structures in French intonation. The Hague: Holland Academic Graphics.

Prince, Alan, and Paul Smolensky. 1993. Optimality theory: constraint interaction in generative grammar RuCCS Technical Report \#2, ROA-537, 262 pp. Rutgers University Center for Cognitive Science.

Prince, Alan, and Paul Smolensky. 2004. Optimality theory: constraint interaction in generative grammar. Oxford: Blackwell.

Pysz, Agnieszka. 2006. The structural location of adnominal adjectives: prospects for old English. SKASE Journal of Theoretical Linguistics 3: 59-85.

Rizzi, Luigi. 1997. The fin structure of the left periphery. In Handbook in generative syntax, ed. Liliane Haegeman, 281-337. Dordrecht: Kluwer.

Rizzi, Luigi. 2004. Locality and left periphery. In Structures and beyond: the cartography of syntactic structures, ed. Adriana Belletti, Vol. 3, 223-251. Oxford: Oxford University Press.

Rutkowski, Pawet, and Ljiljana Progovac. 2006. Classifying adjectives and noun movement in Lithuanian. In Minimalist views on language design: proceedings of the 8th Seoul international conference on generative grammar, ed. C. Yim, 265-277. Seoul: Hankook Korean Generative Grammar Circle.

Samek-Lodovici, Vieri. 2005. Prosody-syntax interaction in the expression of focus. Natural Language and Linguistic Theory 23: 687-755.

Selkirk, Elisabeth. 1984. Phonology and syntax: the relation between sound and structure. Cambridge: MIT Press.

Selkirk, Elisabeth. 1986. On derived domains in sentence phonology. Phonology Yearbook 3: 371-405.

Selkirk, Elisabeth. 1995. Sentence prosody: Intonation, stress, and phrasing. In The handbook of phonological theory, eds. John A. Goldsmith, 550-569. Oxford: Blackwell.

Selkirk, Elisabeth. 2000. The interaction of constraints on prosodic phrasing. In Prosody: theory and experiment, ed. Merle Horne, 231-261. Dordrecht: Kluwer Academic.

Selkirk, Elisabeth. 2004. Bengali intonation revisited. In Topic and focus: a crosslinguistic perspective, eds. Chungmin Lee, Matthew Gordon, and Daniel Büring, 217-246. Dordrecht: Kluwer Academic.

Shlonsky, Ur. 2004. The form of Semitic noun phrases. Lingua 114: 1465-1526.

Sproat, Richard, and Chilin Shih. 1991. The cross-linguistic distribution of adjective ordering restrictions. In Interdisciplinary approaches to language: essays in honor of S.Y. Kuroda, eds. Carol Georgopoulos and Roberta Ishihara, 565-593. Dordrecht: Kluwer Academic.

Svenonius, Peter. 1994. The structural location of the attributive adjective. In WCCFL 12: The proceedings of the 12th west coast conference on formal linguistics, eds. Eric Duncan, Donka Farkas, and Philip Spaelti, 438-454. Stanford: CSLI.

Truckenbrodt, Hubert. 1995. Phonological phrases: their relation to syntax, focus, and prominence. Doctoral Dissertation, MIT.

Truckenbrodt, Hubert. 1999. On the relation between syntactic phrases and phonological phrases. Linguistic Inquiry 30: 219-255.

Umeda, Noriko, and Ann Marie S. Quinn. 1981. Word duration as an acoustic measure of boundary perception. Journal of Phonetics 9: 19-28.

Vaissière, Jacqueline. 1983. Language-independent prosodic features. In Prosody: models and measurements, eds. Anne Cutler and Robert Ladd, 53-66. Berlin: Springer.

Valois, Daniel. 1991. The internal syntax of DP. Doctoral dissertation, University of California.

Wightman, Colin W., Stefanie Shattuck-Hufnagel, Mari Ostendorf, and Patti J. Price. 1992. Segmental durations in the vicinity of prosodic phrase boundaries. Journal of the Acoustical Society of America 91: 1707-1717.

Willis, David. 2006. Against N-raising and NP-raising analyses of Welsh noun phrases. Lingua 116: 18071839.

Zamparelli, Roberto. 1995. Layers in the Determiner Phrase. Doctoral Dissertation, University of Rochester. 